\title{
Modeling of land surface evaporation by four schemes and comparison with FIFE observations
}

\author{
Fei Chen, ${ }^{1}$ Kenneth Mitchell, ${ }^{2}$ John Schaake, ${ }^{3}$ Yongkang Xue, ${ }^{4}$ Hua-Lu Pan, ${ }^{2}$ \\ Victor Koren, ${ }^{3}$ Qing Yun Duan, ${ }^{3}$ Michael Ek, ${ }^{5}$ and Alan Betts ${ }^{6}$
}

\begin{abstract}
We tested four land surface parameterization schemes against long-term (5 months) area-averaged observations over the $15 \mathrm{~km} \times 15 \mathrm{~km}$ First International Satellite Land Surface Climatology Project (ISLSCP) Field Experiment (FIFE) area. This approach proved to be very beneficial to understanding the performance and limitations of different land surface models. These four surface models, embodying different complexities of the evaporation/hydrology treatment, included the traditional simple bucket model, the simple water balance (SWB) model, the Oregon State University (OSU) model, and the simplified Simple Biosphere (SSiB) model. The bucket model overestimated the evaporation during wet periods, and this resulted in unrealistically large negative sensible heat fluxes. The SWB model, despite its simple evaporation formulation, simulated well the evaporation during wet periods, but it tended to underestimate the evaporation during dry periods. Overall, the OSU model ably simulated the observed seasonal and diurnal variation in evaporation, soil moisture, sensible heat flux, and surface skin temperature. The more complex SSiB model performed similarly to the OSU model. A range of sensitivity experiments showed that some complexity in the canopy resistance scheme is important in reducing both the overestimation of evaporation during wet periods and underestimation during dry periods. Properly parameterizing not only the effect of soil moisture stress but also other canopy resistance factors, such as the vapor pressure deficit stress, is critical for canopy resistance evaluation. An overly simple canopy resistance that includes only soil moisture stress is unable to simulate observed surface evaporation during dry periods. Given a modestly comprehensive time-dependent canopy resistance treatment, a rather simple surface model such as the OSU model can provide good areaaveraged surface heat fluxes for mesoscale atmospheric models.
\end{abstract}

\section{Introduction}

The Global Energy and Water Cycle Experiment (GEWEX) includes an initiative known as the GEWEX Continental-Scale International Project (GCIP). The primary objective of GCIP is to understand the atmospheric and land surface hydrological and energy cycles over large continental areas. Because observations of key surface fields such as evaporation and soil moisture are not available on continental scales, much of the desired understanding must be derived from four-dimensional data assimilation systems. Both for this purpose and to improve operational forecasts (especially rainfall and boundary layer forecasts), a series of GCIP initiatives has been undertaken (K. E. Mitchell, preprint, 1994) at the National Meteorological Center (NMC). Two of these GCIP initiatives are (1)

\footnotetext{
${ }^{1}$ University Corporation for Atmospheric Research visiting scientist, Development Division, National Weather Service/NOAA, Camp Springs, Maryland.

${ }^{2}$ Development Division, National Weather Service/NOAA, Camp Springs, Maryland.

${ }^{3}$ Office of Hydrology, National Weather Service/NOAA, Silver Spring, Maryland.

${ }^{4}$ Center for Ocean-Land-Atmosphere Studies, Calverton, Maryland.

${ }^{5}$ College of Oceanic and Atmospheric Sciences, Oregon State University, Corvallis, Oregon.

${ }^{6}$ Atmospheric Research, Pittsford, Vermont.

Copyright 1996 by the American Geophysical Union.

Paper number 95JD02165.

0148-0227/96/95JD-02165\$05.00
}

to upgrade the land surface physics in NMC's mesoscale Eta model [Janjic, 1994; Black, 1994] from a simple bucket model to a multilayer surface model including a sound treatment of canopy resistance, infiltration, and runoff; and (2) to develop a continuously cycled land-surface data assimilation system (LDAS). In the LDAS the land surface physics in the Eta model will be executed "off-line," that is, external to the Eta model, yet virtually in real time by using gridded hourly analyses of observed precipitation, surface radiation, surface winds, temperature, and humidity in order to provide more accurate initial soil moisture conditions for the Eta model. Clearly, selecting a sound land surface parameterization is critical to achieving these goals.

For more than a decade it has been widely accepted that land surface processes play an important role not only in largescale atmospheric models including general circulation models (GCMs) as shown by Mintz [1981] and Rowntree [1983], among many others, but also in regional and mesoscale atmospheric models [Rowntree and Bolton, 1983; Ookouchi et al., 1984; Mahfouf et al., 1987; Avissar and Pielke, 1989; Chen and Avissar, 1994a, 1994b; etc.]. To attempt to represent more accurately the land-atmosphere interactions, many land surface parameterization schemes have been developed, evident in the review papers of Avissar and Verstraete [1990] and Garratt [1993]. Some schemes [e.g., Entekhabi and Eagleson, 1989; Wood et al., 1992; Schaake et al., this issue] are based on the understanding of the long-term hydrological cycle and implicitly treat the effect of the vegetation canopy on evapotranspiration. By con- 
trast, other models [e.g., Deardorff, 1978; Pan and Mahrt, 1987; Dickinson, 1984; Sellers et al., 1986; Noilhan and Planton, 1989; Xue et al., 1991] introduce an explicit treatment of the canopy. These models are based on recent understanding of momentum, heat, and moisture transport in the soil-vegetationatmosphere system, usually over small scales. This explicit canopy treatment is modest in some models [e.g., Deardorf, 1978; Pan and Mahrt, 1987; Noilhan and Planton, 1989] but rather complex in other models [e.g., Dickinson, 1984; Sellers et al., 1986; Xue et al., 1991]. The complex models employ a comprehensive treatment of biophysical and radiation interactions between soil surface, vegetation, and the atmosphere, and, of course, have substantially more specified physical parameters than the more modest canopy models.

Given such a wide spectrum of land surface models, it is a big challenge for atmospheric modelers to select a land surface scheme appropriately adapted to their needs. For example, the implementation of a land surface scheme in operational numerical weather prediction (NWP) models is strongly dependent on the practical constraints of the computer environments of each NWP model [Blondin, 1991]. Even more challenging, given land surface subgrid-scale variability, is the difficulty of operationally specifying a potentially vast set of physical parameters over continental domains on a daily, real-time, annual cycle basis, as required by some vegetation/soil models. This challenge makes the use of complex land surface schemes quite unattractive. Thus we search for a land surface model with relatively few parameters for real-time, year-round, continental domain application, but still capable of reflecting the major effects of canopy resistance on land surface evaporation.

A rational approach for choosing an appropriate land surface scheme is to test different candidate models under the same long-term atmospheric forcing conditions and to validate the models with observed surface fluxes and hydrological variables such as runoff, soil moisture, etc. However, as indicated by Bougeault [1991], most such test simulations to date span only several days or employ only one model. For example, in the past the OSU model had been tested for several days [Mahrt and Pan, 1984; Pan and Mahrt, 1987; Kim and Ek, 1995]. Even though the timescale required by a regional short-term NWP model is about 2 or 3 days, it is important for continuously cycled data assimilation systems, such as in the aforementioned LDAS or that in work by Viterbo and Beljaars [1995], to perform long-term test runs to understand how a land surface scheme simulates the seasonal and multiyear evolution of different components affecting the surface energy balance, particularly the long-term evolution of soil moisture. Also, long-term testing provides an excellent demonstration of the systematic differences of the schemes, as demonstrated by the Project for Intercomparison of Land Surface Parameterization Schemes (PILPS) initiative [Henderson-Sellers et al., 1995].

However, the verification of land surface schemes is further complicated by the spatial scaling problem of subgrid variability. For example, different land surface models have been designed over different time and spatial scales from a "big leaf" to large river basins, but most models have been verified with single-point measurements. Such models are then applied, however, to atmospheric models with a grid resolution ranging from $100 \mathrm{~m} \times 100 \mathrm{~m}$ (large-eddy simulation models) to $100 \mathrm{~km}$ $\times 100 \mathrm{~km}$ (GCMs). Since a grid box in an atmospheric model represents an area average, it is necessary to verify land surface model simulations by area-averaged observations. Ideally, the size of the observation area is close to the grid resolution of the atmospheric models to which the land surface model is supposed to apply.

For the above reasons the data collected during the First ISLSCP (International Satellite Land Surface Climatology Project) Field Experiments (FIFE) [Sellers et al., 1992a] provides a valuable opportunity to verify surface models. The 15 $\mathrm{km} \times 15 \mathrm{~km}$ area-averaged FIFE data set of A. K. Betts and J. H. Ball (1993) (data available from the authors) contains atmospheric forcing data, surface fluxes (during IFCs), and soil moisture content for about 5 months (from May 22 to October 16, 1987). In this study we use this area-averaged FIFE data to force and validate four land surface schemes including (1) the simple bucket model with two parameters [Manabe, 1969]; (2) a two-layer water balance model with seven parameters [Schaake et al., this issue]; (3) an extension of the vegetation/ soil model of Pan and Mahrt [1987] with 15 parameters; and (4) the simplified Simple Biosphere (SSiB) model of Xue et al. [1991] with 22 parameters.

The objective of this study is to understand the performance and limitations of surface models embodying very different treatments of the hydrological cycle, and to select an appropriate surface scheme for the NMC mesoscale Eta model and companion LDAS. Furthermore, by driving and verifying these land-surface models with area-averaged data over the $15 \mathrm{~km} \times$ $15 \mathrm{~km}$ FIFE 1987 site (A. K. Betts and J. H. Ball, 1993), this study is expected to provide important insights on the adequacy of different land surface models for use in mesoscale models in general, having grid resolutions of $10-40 \mathrm{~km}$.

The FIFE data used in this work is described in section 2, and the four land surface schemes and the simulation design are presented in section 3 . The simulation results obtained from these four land surface schemes are discussed in section 4 , and the major conclusions are provided in section 5 .

\section{Forcing and Validation Data}

In 1987, extensive surface data were collected over the Konza prairie in Kansas during the FIFE experiment [Sellers et al., 1992a]. The data used in this study is a single spatial mean time series, with a time interval of $30 \mathrm{~min}$, derived by $\mathrm{A}$. $\mathrm{K}$. Betts and J. H. Ball (1993) by averaging data collected over different stations in the FIFE area of $15 \mathrm{~km} \times 15 \mathrm{~km}$. The PAM (portable automated mesonet) station time series data (30-min averages at about 10 stations) consisted of atmospheric forcing data such as wind, air temperature and humidity, precipitation, incoming and reflected solar radiation, net radiation and incoming longwave radiation, a radiometric measure of the ground surface temperature, and ground temperature at 10 and $50 \mathrm{~cm}$ below the surface. The spatial mean PAM station forcing data spanning May 22 to October 16, 1987, was used to drive the land surface schemes here.

For validation, this data set also includes the spatial mean surface sensible heat, latent heat, and ground heat fluxes averaged over 17 selected surface flux stations, which made measurements using both eddy correlation and Bowen ratio methods [Betts et al., 1993]. These surface flux stations also measured the aforementioned four radiation components and net radiation. According to Betts et al. [1993], the radiation averages obtained from the flux stations, which have lower incoming solar radiation and a higher albedo, are internally more self-consistent than the radiation data obtained from the PAM stations. Thus, in the input radiative forcing conditions 
(i.e., net solar and downward longwave), we have replaced the PAM station radiation by the flux station radiation whenever the latter was available in order to achieve better consistency between model input radiative forcing and validating observed heat fluxes. The averaged heat flux observations from the flux stations, only available for four intensive field campaigns (IFCs), were extensively used to validate the model simulated fluxes. The dates of these IFC periods are May 26-June 6, June 25-July 11, August 6-21, and October 5-16, respectively. For validation beyond these IFC periods we use the longerterm (from May 27 to October 16) but spatially less representative (two stations) time series of FIFE observed surface fluxes of Smith et al. [1992].

\section{Land-Surface Schemes}

In this study we test the four land surface schemes cited in the introduction. Our particular choice of schemes was heavily motivated by wanting a small set of schemes that spanned both (1) the inclusion of few or many parameters and (2) the inclusion or omission of an explicit vegetation canopy. In addition, we wanted schemes whose principal developers were readily at hand for in-person consultation.

Both the soil/vegetation model of Pan and Mahrt [1987] (herein called the OSU (Oregon State University) model) and that of Xue et al. [1991] (herein called the SSiB model) have an explicit vegetation canopy, soil hydrology, and soil thermodynamics. In contrast, the well-known bucket evaporation model of Manabe [1969] (herein called the bucket model) and the new two-layer simple water balance model of Schaake et al. [this issue] (herein called the SWB (simple water balance) model) have no explicit vegetation or soil thermodynamics, but only simple soil hydrology components that require only precipitation and potential evaporation as inputs. In testing the bucket model or SWB model, we use the OSU model as the parent model (test bed), wherein the OSU evaporation/ hydrology component is replaced by one of these two schemes, respectively, while retaining the OSU thermodynamics and potential evaporation. These three models will be discussed together in section 3.1. We choose the OSU model for this parent model role because it utilizes an explicit, easily identified potential evaporation component $\left(E_{p}\right)$. In the SSiB model, described separately in section $3.2, E_{p}$ is not easily separated from that model's more complex treatment of can-

Table 1. Specification of Parameters in the Bucket and SWB Surface Models

\begin{tabular}{|c|c|}
\hline Parameter & Value \\
\hline \multicolumn{2}{|l|}{ Bucket } \\
\hline Maximum water holding capacity $W_{\max }, \mathrm{m}$ & 0.27 \\
\hline Field capacity $W_{c r}, \mathrm{~m}$ & 0.203 \\
\hline \multicolumn{2}{|l|}{$S W B$} \\
\hline $\begin{array}{l}\text { Maximum soil moisture deficit in the surface layer } \\
D 1_{\text {max }}, \mathrm{m}\end{array}$ & 0.015 \\
\hline $\begin{array}{l}\text { Maximum soil moisture deficit in the deep layer } \\
D 2_{\max }, \mathrm{m}\end{array}$ & 0.255 \\
\hline Potential subsurface flow $Q_{\max }$, m day $^{-1}$ & 0.03 \\
\hline Bottom layer depth producing subsurface flow $Q c$ & 0.5 \\
\hline Timescaling parameter $Q t$ & 3.0 \\
\hline Soil density $\eta, \mathrm{g} \mathrm{cm}^{-3}$ & 1.5 \\
\hline Soil porosity $\Theta s, \mathrm{~m}^{3} \mathrm{~m}^{-3}$ & 0.464 \\
\hline
\end{tabular}

SWB, simple water balance.
Table 2. Soil- and Vegetation-Related Parameters Used in the OSU and SSiB Models

\begin{tabular}{|c|c|}
\hline Parameters & Value \\
\hline \multicolumn{2}{|c|}{ Soil parameters } \\
\hline Soil porosity $\Theta s, \mathrm{~m}^{3} \mathrm{~m}^{-3}$ & 0.464 \\
\hline Saturation soil suction $\Psi_{s}, \mathrm{~m}$ & -0.62 \\
\hline $\begin{array}{l}\text { Saturation hydraulic conductivity } \\
\qquad K_{s}, \mathrm{~m} \mathrm{~s}^{-1}\end{array}$ & $7.1 \times 10^{-6}$ \\
\hline 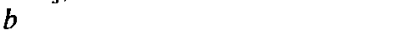 & 8.72 \\
\hline Field capacity $\Theta_{\mathrm{ref}}, \mathrm{m}^{3} \mathrm{~m}^{-3}$ & 0.38 \\
\hline Wilting point $\Theta_{w}, \mathrm{~m}^{3} \mathrm{~m}^{-3}$ & 0.11 \\
\hline \multicolumn{2}{|c|}{ Vegetation parameters } \\
\hline $\begin{array}{l}\text { Minimum stomatal resistance } \\
R_{c \min },{ }^{*} \mathrm{~S} \mathrm{~m}^{-1}\end{array}$ & 40 \\
\hline Rooting depth, $\uparrow \mathrm{m}$ & 1 \\
\hline Maximum canopy capacity, ${ }^{*} \dagger$ m & 0.0005 \\
\hline Roughness length $Z_{0},{ }^{*} \dagger \mathrm{m}$ & 0.045 \\
\hline Parameters in the $F 1^{*}$ & $A 1=0.55, R_{c \max }=5000$ \\
\hline Parameters in the F3* & $T_{\mathrm{ref}}=298, B 1=0.0016$ \\
\hline Parameter in the $\mathrm{F}^{*}{ }^{*} \dagger$ & $C 2=36.4$ \\
\hline Leaf angle distribution $\dagger$ & 0.01 \\
\hline Soil moisture stress factors $\dagger$ & $c 1=1.3, c 2=6.9$ \\
\hline Temperature stress $\dagger$ & $\begin{array}{c}T_{I}=273, T_{o}=310 \\
T_{h}=328\end{array}$ \\
\hline$r_{s}$ coefficient,$\dagger \mathrm{s} \mathrm{m}^{-1}$ & 118 \\
\hline slope $\dagger$ & 0.0173 \\
\hline$r_{b} \dagger$ & 1.34 \\
\hline$r_{d}^{\dagger}$ & 27.65 \\
\hline Canopy height $\dagger$ & 0.3 \\
\hline Displacement height $\dagger$ & 0.083 \\
\hline
\end{tabular}

Soil parameters are based on data of Cosby et al. [1984]. Vegetation parameters are largely based on the data of Sellers et al. [1992b]. See text for more information regarding the models.

*OSU.

†SSiB.

opy resistance. As each model is presented, the reader is referred to Tables 1 and 2 for model parameter values, which are further discussed in section 3.3. Table 3 contrasts the number of parameters in the four chosen models.

In land surface models that carry soil thermodynamics like the OSU or SSiB models, a measure of scheme complexity is whether the thermodynamic surface energy budget is computed for (1) a single unified ground/vegetation surface (i.e., one surface temperature) or (2) multiple surfaces representing the ground and one or more vegetation canopies (i.e., two or more surface temperatures). The OSU model is an example of the former, while the SSiB model is an example of the latter.

\subsection{OSU, Bucket, and SWB Models}

The OSU land surface scheme is basically the coupling of the diurnally dependent Penman potential evaporation approach of Mahrt and Ek [1984], the multilayer soil model of Mahrt and Pan [1984], and the primitive canopy model of Pan and Mahrt [1987]. In this study the latter OSU canopy model is tested along with the later OSU canopy resistance extension from $E k$ and Mahrt [1991], which largely follows the modestly complex approach of Noilhan and Planton [1989] and Jacquemin and Noilhan [1990] (hereafter NP89 and JN90, respectively). We give here a brief description of the soil thermodynamics and soil hydrology in the OSU model, with an emphasis on its hydrology component as a comparison to the bucket model and the SWB model. Detailed information on the OSU model can be found in work by $E k$ and Mahrt [1991].

Typically, the OSU model is executed with $2-3$ soil layers 
Table 3. Complexity of Land Surface Evaporation/Hydrology Models (Versions) Tested Against FIFE Observations

\begin{tabular}{llccr}
\hline & & \multicolumn{3}{c}{ Parameters } \\
\cline { 3 - 5 } Model & \multicolumn{1}{c}{ Version } & Soil & Vegetation & Total \\
\hline Bucket & $\ldots$ & 2 & $\ldots$ & 2 \\
SWB & No resistance & 7 & $\ldots$ & 7 \\
& Canopy resistance & 7 & 7 & 14 \\
OSU & Constant PC & 6 & 4 & 10 \\
& Canopy resistance & 6 & 9 & 15 \\
SSiB & $\ldots$ & 4 & 18 & 22 \\
\hline
\end{tabular}

PC, plant coefficient.

(though more layers are easily accommodated). In this study, both the OSU model and SSiB model utilize three soil layers: namely, a thin top layer of $5 \mathrm{~cm}$, a second root zone layer of 95 $\mathrm{cm}$, and a third subroot layer of $1 \mathrm{~m}$. The OSU model has one canopy layer and eight prognostic variables: soil moisture and temperature in the three soil layers; water stored on the canopy; and snow stored on the ground. Hereafter in this paper we ignore snow physics, as the FIFE period excludes winter.

3.1.1. OSU thermodynamics. The surface skin temperature is determined following Mahrt and $E k$ [1984] by applying a single linearized surface energy balance equation representing the combined ground/vegetation surface. In companion to this the ground heat flux is controlled by the usual diffusion equation for soil temperature $(T)$ :

$$
C(\Theta) \frac{\partial T}{\partial t}=\frac{\partial}{\partial z}\left(K_{i}(\Theta) \frac{\partial T}{\partial z}\right)
$$

where the volumetric heat capacity $C$ and the thermal conductivity $K_{t}$ are formulated as functions of volumetric soil water content $\Theta$ (fraction of unit soil volume occupied by water). The layer-integrated form of (1) for the $i$ th soil layer is

$$
\Delta z_{t} C_{t} \frac{\partial T_{t}}{\partial t}=\left(K_{t} \frac{\partial T}{\partial z}\right)_{z_{i+1}}-\left(K_{t} \frac{\partial T}{\partial z}\right)_{z_{t}}
$$

The prediction of $T_{t}$ is performed using the fully implicit Crank-Nicholson scheme. In the top layer the last term in (2) represents the surface ground heat flux and is computed using the surface skin temperature. The gradient at the bottom of the model is computed from a specified constant boundary temperature taken as the mean annual surface air temperature.

3.1.2. OSU hydrology. In the hydrology model the prognostic equation for the volumetric soil moisture content $(\Theta)$ is

$$
\frac{\partial \Theta}{\partial t}=\frac{\partial}{\partial z}\left(D \frac{\partial \Theta}{\partial z}\right)+\frac{\partial K}{\partial z}+F_{\Theta}
$$

where both the soil water diffusivity $D$ and hydraulic conductivity $K$ are functions of $\Theta$, and $F_{\Theta}$ represents sources and sink (i.e., precipitation and evaporation) for soil water. The above is the diffusive form of Richard's equation, derived from Darcy's law under the assumption of a rigid, isotropic, homogeneous, one-dimensional vertical flow domain [see Hanks and Ashcroft, 1986 , pp. 62-78], and thereby the soil water diffusivity $D$ is given by $D=K(\Theta)[\partial \Psi / \partial \Theta]$ wherein $\Psi$ is the soil water tension function. Here we apply the Cosby et al. [1984] functions for $K$ and $\Psi$ given by $K(\Theta)=K_{s}\left(\Theta / \Theta_{s}\right)^{2 b+3}$ and $\Psi(\Theta)$ $=\Psi_{s} /\left(\Theta / \Theta_{s}\right)^{b}$, where the parameters $K_{s}, \Psi_{s}, \Theta_{s}$, and $b$ are given in Table 2. In work by Cuenca et al. [this issue] the sensitivity of the OSU model to the choice of functions for $K(\Theta)$ and $\Psi(\Theta)$ is examined for a bare soil case.

Integrating (3) over three soil layers and expanding $F_{\Theta}$, we obtain

$$
\begin{aligned}
& d_{z_{1}} \frac{\partial \Theta_{1}}{\partial t}=-D\left(\frac{\partial \Theta}{\partial z}\right)_{z_{1}}-K_{z_{1}}+P_{d}-R-E_{\mathrm{dir}}-b_{1} E_{t} \\
& d_{z_{2}} \frac{\partial \Theta_{2}}{\partial t}=D\left(\frac{\partial \Theta}{\partial z}\right)_{z_{1}}-D\left(\frac{\partial \Theta}{\partial z}\right)_{z_{2}}+K_{z_{1}}-K_{z_{2}}-b_{2} E_{t}
\end{aligned}
$$

$$
d_{z_{3}} \frac{\partial \Theta_{3}}{\partial t}=D\left(\frac{\partial \Theta}{\partial z}\right)_{z_{2}}+K_{z_{2}}-K_{z_{3}}
$$

where $d_{z}$ is the $i$ th soil layer thickness. $P_{d}$ is the precipitation not intercepted by the canopy. $R$ is the surface runoff and specified by the SWB surface runoff formulation, which is a hydrological approach that considers the subgrid-scale variability in precipitation and soil moisture (see $Q s$ in section 3.1.4). $E_{t}$ is the canopy transpiration, which is partitioned between layers 1 and 2 according to the weights $b_{1}=d_{z_{1}} /\left(d_{z_{1}}+d_{z_{2}}\right)$ and $b_{2}=d_{z_{2}} /\left(d_{z_{1}}+d_{z_{2}}\right) . K_{z_{3}}$ is the moisture loss due to "gravitational" percolation through the bottom of the third layer, also named subsurface runoff or drainage.

The total evaporation $E$ from the soil canopy surface, used in the single surface energy balance, is the sum of the direct evaporation from the top shallow soil layer, $E_{\mathrm{d} \text { Ir }}$, evaporation of precipitation intercepted by the canopy, $E_{c}$, and transpiration via canopy and roots, $E_{t}$.

$$
E=E_{\mathrm{drr}}+E_{t}+E_{c}
$$

The direct evaporation from the ground surface is determined by

$$
E_{\mathrm{d} 1 \mathrm{r}}=\left(1-\sigma_{f}\right) M I N\left(\left[-D\left(\frac{\partial \Theta}{\partial z}\right)_{z_{1}}-K_{z_{1}}\right], E_{p}\right)
$$

where $E_{p}$ is the potential evaporation and $\sigma_{f}$ is the green vegetation fraction, both described after the next paragraph. The direct evaporation can proceed at the potential rate $E_{p}$ when the soil moisture at the surface is rather moist. Otherwise, direct evaporation can proceed only at the rate by which the top soil layer can transfer water upward from below.

The wet canopy evaporation is determined by

$$
E_{c}=\sigma_{f} E_{p}\left(\frac{W_{c}}{S}\right)^{n}
$$

where $W_{c}$ is the intercepted canopy water content, and $S$ is the maximum allowed $W_{c}$ capacity, chosen here to be $0.5 \mathrm{~mm} ; n=$ 0.5. This is formulated similarly to NP89 and JN90. The intercepted canopy water budget is governed by

$$
\frac{\partial W_{c}}{\partial t}=\sigma_{f} P-D-E_{c}
$$

wherein $P$ is the input total precipitation. If $W_{c}$ exceeds $S$, the excess precipitation or drip $D$ reaches the ground (note that $P_{d}=\left(1-\sigma_{f}\right) P+D$ in (4)). The canopy evapotranspiration is determined by

$$
E_{t}=\sigma_{f} E_{p} B_{c}\left[1-\left(\frac{W_{c}}{S}\right)^{n}\right]
$$


Table 4. Seasonal Cycle, From May to October 1987 Over FIFE Area, of Vegetation Parameters Used in the OSU and SSiB Models

\begin{tabular}{lllllll}
\hline & \multicolumn{6}{c}{ Month } \\
\cline { 2 - 7 } & May & June & July & Aug. & Sept. & Oct. \\
\hline LAI & 1.60 & 2.20 & 2.20 & 2.0 & 1.00 & 0.50 \\
$\sigma_{f}$ & 0.78 & 0.83 & 0.80 & 0.82 & 0.75 & 0.39 \\
\hline
\end{tabular}

The green leaf area index (LAI) is based on the FIFE measurements of Kim and Verma [1990], while the green vegetation fraction $\sigma_{f}$ is derived from a 5-year climatology of NDVI [Gutman et al., 1995] applied at the FIFE location (G. Gutman, personal communication, 1994).

where $B_{c}$ embodies canopy resistance, including soil moisture stress. The factor $\left(W_{c} / S\right)^{n}$ serves as a weighting coefficient to suppress $E_{t}$ in favor of $E_{c}$ as the canopy surface becomes increasingly wet.

Recalling (7), the drying cycle timescales of $E_{\mathrm{d} \mathrm{rr}}$ or $E_{c}$ versus $E_{t}$ are quite different. $E_{\mathrm{d} \iota r}$ and $E_{c}$ represent fast changing evaporation due to small water capacity and low resistance, while the higher resistance in $E_{t}$ combined with the deep root zone maintain relatively high evaporation for several weeks or more following the last significant rainfall. A major focus of the present study is the important role of the canopy resistance treatment in (11). But first we discuss the roles of $\sigma_{f}$ and $E_{p}$.

The green vegetation fraction $\sigma_{f}$ is defined as the grid cell fraction wherein midday downward solar insolation is intercepted by photosynthetically active green canopy. Equations (8), (9), and (11) show that it acts as a fundamental weighting coefficient between the three components of evaporation in (7). The sensitivity tests of JN90 showed it to be an important first-order parameter. It is important therefore to specify its seasonal cycle in operational NWP models and GCM applications. See Table 4 for a description of the time-dependent $\sigma_{f}$ values used in the present FIFE simulations.

It can be shown from (8), (9), and (11) that each component of $E$ in (7) and $E$ itself are bounded by the potential evaporation $E_{p}$, which is calculated in the OSU model using a Penman-based energy balance approach [Mahrt and $E k, 1984$ ]. The Mahrt and Ek derivation of $E_{p}$ imposes a saturated ground surface and zero canopy resistance while combining a bulk aerodynamic formulation (including a stability-dependent surface exchange coefficient or aerodynamic resistance) with a surface energy balance expression to yield a diurnally varying potential evaporation $E_{p}$. This approach, as demonstrated by $P a n$ [1990], avoids the common overestimation of $E_{p}$ by the traditional bulk aerodynamic approach, which ignores energy balance. Hence some models, unfortunately, adopt a considerable complexity in canopy resistance in $E_{l}$, while failing to constrain $E_{p}$ by energy balance.

In the OSU model, historically there are two approaches for calculating the resistance term $B_{c}$. The earlier primitive but appealing form of Pan and Mahrt [1987] is

$$
B_{c}=P_{c} F_{4}
$$

where $P_{c}$ is a constant "plant coefficient" between 0 and 1 depending on the vegetation species (typically around 0.8 and meant to crudely capture a minimal stomatal resistance effect). $F_{4}$ is a soil moisture stress function also between 0 and 1 and described below. The later extended form of $B_{c}$ including explicitly the canopy resistance [Ek and Mahrt, 1991] is

$$
B_{c}=\frac{1+\Delta / R_{r}}{1+R_{c} C_{h}+\Delta / R_{r}}
$$

where $C_{h}$ is the surface exchange coefficient for heat and moisture. $\Delta$ depends on the slope of the saturation specific humidity curve. $R_{r}$ is a function of surface air temperature, surface pressure, and $C_{h} . R_{c}$ is the canopy resistance including $F_{4}$. Details on $C_{h}, R_{r}$, and $\Delta$ are provided by $E k$ and Mahrt [1991]. Here we focus on the canopy resistance, $R_{c}$.

Jarvis [1976] proposed a parameterization of $R_{c}$ based on the product of several different stress factors. This type of relationship is used in many land surface models [e.g., NP89; JN90; Acs, 1994; Pleim and Xiu, 1995]. The canopy resistance $R_{c}$ is calculated here following the formulation of JN90:

$$
\begin{gathered}
R_{c}=\frac{R_{c \mathrm{~m} ! \mathrm{n}}}{\mathrm{LAI}_{1} F_{2} F_{3} F_{4}} \\
F_{1}=\frac{R_{c \mathrm{~min}} / R_{c \max }+f}{1+f} \text { where } f=0.55 \frac{R_{g}}{R_{g l}} \frac{2}{\mathrm{LAI}} \\
F_{2}=\frac{1}{1+\beta\left[q^{*}\left(T_{a}\right)-q_{a}\right]} \\
F_{3}=1-B 1\left(T_{\mathrm{rel}}-T_{a}\right)^{2} \\
F_{4}=\sum_{t=1}^{2} \frac{\left(\Theta_{t}-\Theta_{w}\right) d_{z_{t}}}{\left(\Theta_{\mathrm{ref}}-\Theta_{w}\right)\left(d_{z 1}+d_{z 2}\right)}
\end{gathered}
$$

where $R_{c \text { min }}$ is the minimum stomatal resistance, and LAI, the leaf area index. The functions $F_{1}, F_{2}, F_{3}$, are all subject to 0 and 1 as lower and upper bounds and they respectively represent the effects of solar radiation, vapor pressure deficit, and air temperature. The definition and values of various parameters in $F_{1}$, and $F_{3}$ are described in NP89 and JN90. $F_{2}$ is the same as defined by Xue et al. [1995].

The soil moisture stress function $F_{4}$ typically embodies a linear relationship in soil moisture stress between the field capacity $\Theta_{\text {ref }}$ and the wilting point $\Theta_{w}$. This linear function is widely used in land surface models, for example, those of Mahrt and Pan [1984], Blondin and Bottger [1987], JN90, Pleim and Xiu [1995], Kim and Ek [1995], etc. However, our sensitivity study (not shown) showed that the typical use of a narrow range of $\Theta_{\text {ref }}-\Theta_{w}$ in $F_{4}$ tends to overestimate the evaporation during wet periods and underestimate the evaporation during dry periods when validated against the area-averaged FIFE observations here. One chief reason for this bias is that the spatial distribution of soil moisture and hence evaporation is rarely homogeneous in the natural world. Even though the area-averaged soil moisture represented by a grid box of an atmospheric model is at the wilting point (so, no evaporation according to $F_{4}$ ), the soil moisture in some subarea can be higher than the wilting point and vice versa. Therefore evaporation does occur over these subgrid areas and is significant during dry periods. For example, several observations [Smith et al., 1992; Stewart and Verma, 1992] in the FIFE area during the driest period, that is, July 25-30, 1987, demonstrated that the evaporation from the wetter-than-wilting-point area is important. Additionally, the FIFE study by Duan et al. [this issue] clearly demonstrates the significant spatial variability of soil moisture and $E$ across the FIFE sites. 


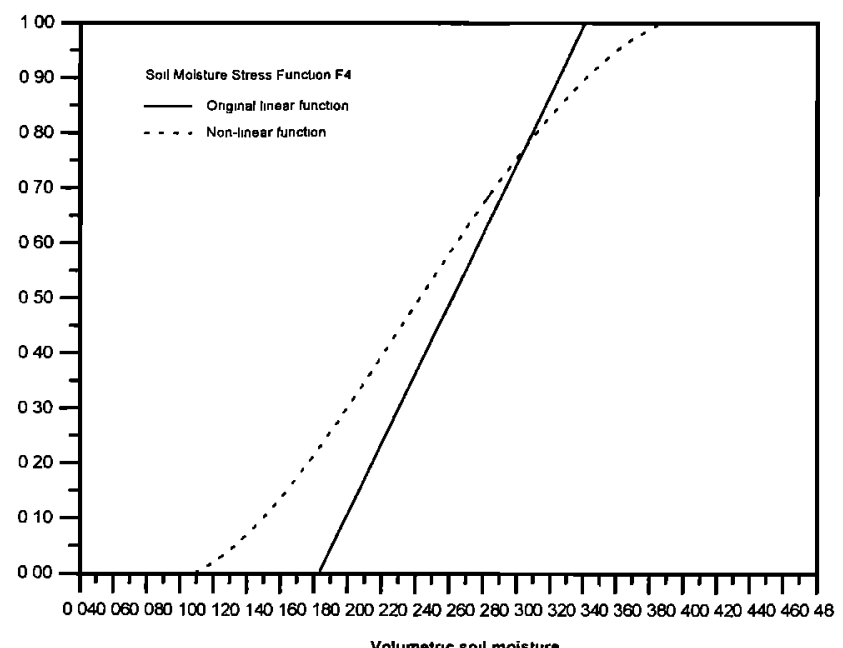

Figure 1. The nonlinear soil moisture stress function adapted for the FIFE case versus a linear soil moisture stress function.

In approaching the subgrid-scale variability of soil moisture in a simple way, we used a new nonlinear soil moisture stress function, inspired from the subgrid soil moisture variability work of Wetzel and Chang [1987], to maintain the evaporation beyond the wilting point and to reduce the evaporation when the area-averaged soil moisture is near the field capacity, as illustrated by the 5 -month area-averaged surface evaporation observations (A. K. Betts and J. H. Ball, 1993). A comparison between the original linear soil moisture stress function of $F_{4}$ and the new function we adapted for the FIFE case is illustrated in Figure 1. Our original value of $\Theta_{w}=0.183$ and $\Theta_{\text {ref }}$ $=0.34$ in function $F_{4}$ (solid curve in Figure 1) were derived from the criteria given by Hillel [1980]. Our final values of $\Theta_{w}$ $=0.11$ and $\Theta_{\text {ref }}=0.38$ were chosen empirically. The empirical nonlinear function $F_{4}$ (dashed curve in Figure 1) is used in the OSU model for this study.

3.1.3. Bucket model hydrology. The simple bucket model constructed for this study is similar to the traditional bucket model, such as that described in the work of Manabe [1969] and Robock et al. [1995]. The only prognostic variable in this model is the bucket water content $W$ (implicitly representing the available soil moisture for evaporation in the uppermost 1 $\mathrm{m}$ of soil) and is calculated from

$$
\frac{\partial W}{\partial t}=P-R-E
$$

where $P$ is the precipitation rate, $E$ the evaporation rate, and $R$ the runoff, which is produced only if the bucket is full. The bucket model evaporates at the potential rate $E_{p}$ when $W$ exceeds a critical value $W_{c r}$, which is assumed to be $75 \%$ of the maximum water holding capacity $W_{\max }$. Thus the evaporation $E$ is

$$
\begin{gathered}
E=\beta E_{p} \\
\beta=1 \quad \text { if } W \geq W_{c r} \\
\beta=\frac{W}{W_{c r}} \quad \text { otherwise }
\end{gathered}
$$

3.1.4. SWB model hydrology. The SWB model is a twolayer or two-reservoir simple water balance model (i.e., with upper and lower "buckets") and accounts for the spatial heterogeneity of rainfall, soil moisture, and runoff. It has been developed by Schaake et al. [this issue] and is typically calibrated for a given river basin [Schaake et al., this issue]. Here the SWB model was not calibrated for a FIFE basin. Rather, parameters were estimated from a knowledge of FIFE site characteristics and model experience over similar areas. The model includes seven parameters and like the bucket model requires only rainfall and potential evaporation as input. The upper layer is assumed to be a thin layer or shallow bucket with fast changing water storage, whereas the lower layer or deep bucket has a large capacity. The shallow upper bucket acts to allow significant runoff well before the deep layer bucket is full and thereby avoids the major problem of very low runoff in the traditional bucket model above. The predicted variable in the SWB model is the soil moisture deficit (i.e., maximum water capacity minus present water content). When a bucket is full of water, its soil moisture deficit is zero. In the version of the SWB model that we adapted for this FIFE case, the prognostic equations for the upper layer soil moisture deficit $D(1)$ and the bottom layer soil moisture deficit $D(2)$ are

$$
\begin{gathered}
\frac{\partial D(1)}{\partial t}=E u-(P-P x) \\
\frac{\partial D(2)}{\partial t}=E b-(P x-Q s)+Q g
\end{gathered}
$$

where $P$ is the rainfall rate and $P x$ the excess precipitation passed into the bottom layer according to $P x d t=P d t-$ $D(1)$ ( $d t$ is the time step). The total evaporation is $E u+E b$, where $E u$ and $E b$ are evaporation from upper and bottom layer respectively and calculated as

$$
\begin{gathered}
E u=E_{p}\left(1-\frac{D(1)}{D 1_{\max }}\right) \\
E b=E_{p}\left(\frac{D(1)}{D 1_{\max }}\right)\left(1-\frac{D(2)}{D 2_{\max }}\right)
\end{gathered}
$$

where $E_{p}$ is the potential evaporation rate. $D 1_{\max }$ and $D 2_{\max }$ are the maximum soil moisture deficit of the upper and bottom layer, respectively. Note that in (20) and (21), as in (16) and (17), only soil moisture depletion acts as a source of evaporative stress. Later, in a sensitivity test discussed in section 4.3.2, we examine the impact on the SWB model of adding a canopy resistance term following (13) and (14).

The surface runoff $Q s$ and subsurface runoff $Q g$ are defined as

$$
\begin{gathered}
Q s=P x\left(\frac{P x}{P x+D_{\text {eff }}}\right) \\
Q g=Q_{\max }\left(1-\frac{D(2)}{S_{\max }}\right)^{4} \quad \text { if } D(2)<S_{\max } \\
Q g=0 \quad \text { otherwise }
\end{gathered}
$$

where $Q_{\max }$ is the maximum rate of subsurface runoff, $S_{\max }$ $\left(S_{\max }=D 2_{\max } \times Q c\right)$, a critical value of soil moisture deficit. $D_{\text {eff }}$ is an effective soil moisture deficit depending on a timescaling parameter $Q t$ and the soil moisture content of the bottom layer. Unlike the bucket model, the SWB model has a subsurface runoff which is typically nonzero. The specification 
of SWB model parameters used in this study can be found in Table 1.

\subsection{SSiB Model}

The SSiB model [Xue et al., 1991] is a biophysically based model of land-surface-atmosphere interaction. It has three hydrological soil layers, one thermodynamic soil slab, one canopy layer, and eight prognostic variables: soil wetness in the three soil layers; temperature at the canopy, ground surface, and bottom boundary; water stored on the canopy; and snow stored on the ground.

3.2.1. SSiB thermodynamics. The governing equation for canopy temperature $T_{c}$ is based on the energy conservation equation

$$
C_{c} \frac{\partial T_{c}}{\partial t}=R_{n c}-H_{c}-\lambda E_{w}
$$

where $C_{c}$ is the heat capacity of canopy, and $\lambda$ the latent heat of vaporization. $R_{n c}$ and $H_{c}$ are net radiation and sensible heat flux. $E_{w}$ is the sum of evaporation from wet canopy $E_{c}$ and canopy evapotranspiration $E_{t}$, defined later in this section.

The force restore method is used to predict the time variation of the ground temperature $T_{g s}$.

$$
C_{g s} \frac{\partial T_{g s}}{\partial t}=R_{n g s}-H_{g s}-\lambda E_{\mathrm{d} I r}-\frac{2 \pi C_{g s}}{\tau}\left(T_{g s}-T_{d}\right)
$$

where $\tau$ is the day length, $C_{g s}$ the effective heat capacity of soil, $T_{d}$ the temperature for deep soil, and $R_{n g s}, H_{g s}$, and $E_{\mathrm{dir}}$ are net radiation, sensible heat, and direct evaporation at the ground. The equation for deep soil temperature $T_{d}$ is

$$
C_{g s} \frac{\partial T_{d}}{\partial t}=2\left(R_{n g s}-H_{g s}-\lambda E_{\mathrm{drr}}\right) \sqrt{365 \pi}
$$

3.2.2. SSiB hydrology. The governing equation for the canopy interception water store $W_{c}$ is based on water conservation.

$$
\frac{\partial W_{\iota}}{\partial t}=P-D-E_{\iota}
$$

where $P, D$, and $E_{c}$ are the precipitation, canopy drip rate, and evaporation from the wetted portions of the vegetation canopy. In the three soil layers, water movement is described by the finite difference approximation to the diffusion equations.

$$
\begin{gathered}
\frac{\partial S_{1}}{\partial t}=\frac{1}{D_{1}}\left[D-Q_{12}-E_{\mathrm{dtr}}-b_{1} E_{t}\right] \\
\frac{\partial S_{2}}{\partial t}=\frac{1}{D_{2}}\left[Q_{12}-Q_{23}-b_{2} E_{t}\right] \\
\frac{\partial S_{3}}{\partial t}=\frac{1}{D_{3}}\left[Q_{23}-Q_{3}\right]
\end{gathered}
$$

where the $S_{1}, S_{2}$, and $S_{3}$ and $D_{1}, D_{2}$, and $D_{3}$ are water content (in meters) and thickness (in meters) of three soil layers, respectively. $Q i j$ is the transfer of water between $i$ th and $j$ th layers, due to both diffusion and downward percolation. Factors $b_{1}$ and $b_{2}$ partition the canopy transpiration $E_{t}$ between layers 1 and 2 .

The total surface evaporation $E$ in the SSiB model, like the OSU model, is $E=E_{\mathrm{d} ı}+E_{c}+E_{t}$. However, the specific formulations for evaporation in SSiB differ from those in the OSU model. For details the reader is referred to work by Xue et al. [1991]. Here we highlight a few points. The resistance to the transfer of water vapor from the canopy and upper soil layer to the adjacent exterior air includes canopy resistance $r_{c}$ and soil surface resistance $r_{\text {soll }}$, respectively. The results of Camilo and Gurney [1986] were used to curve-fit a simple relationship between soil surface resistance and wetness of the upper $0.5 \mathrm{~cm}$ of the soil. The parameterization of the canopy resistance $r_{c}$ in $\mathrm{SSiB}$ includes three stress functions analogous to $F_{2}, F_{3}$, and $F_{4}$ in (14), which describe the resistance dependence on the atmospheric temperature, the vapor pressure deficit, and the soil water potential. However, the SSiB model drops the simple treatment of biophysical response in $F_{1}$ in favor of a more complex biophysical approach which requires more parameters, as described by Sellers et al. [1986] and Xue et al. [1991].

\subsection{Initialization and Specification of Physical Parameters}

Considerable cooperative joint effort was devoted by the model developers (coauthors) to match parameter values and initial conditions, particularly in the parameter choices for the OSU and SSiB models (to the extent allowed by differences in physical approach). The soil parameters for silty clay loam, the dominant soil texture over the FIFE area, are based on those of Cosby et al. [1984]. Across the FIFE area the natural tall grass of the Konza prairie is the dominant vegetation, and the related vegetation parameters are largely based on FIFE observations [Sellers et al., 1992b]. The specification of vegetation and soil parameters for all four land surface models is summarized in Tables 1,2 , and 4.

Following the experience of PILPS, we took care to match the maximum water-holding capacity among the four models. Based on the actual field capacity and wilting point used in the OSU model (see Table 2 and the limits of the dashed curve in Figure 1), the maximum water-holding capacity in the bucket model and the total soil moisture deficit in the SWB model are chosen to be $270 \mathrm{~mm}$. This is equivalent to the extractable water at field capacity for evaporation in the OSU model.

These four land surface models were integrated in time over 5 months using 30-min time steps from initial conditions at 0000 UT May 22, 1987, to 2330 UT October 16, 1987. All atmospheric forcing conditions, that is, incoming and reflected shortwave radiation, incoming longwave radiation, air temperature and humidity at the height of $10 \mathrm{~m}$ above the ground, precipitation, horizontal wind speed, and surface pressure, are provided at 30 -min intervals by the area-averaged FIFE data of A. K. Betts and J. H. Ball (1993). The OSU model and the $\mathrm{SSiB}$ model have three soil layers whose depths are $0.05,0.95$, and $1 \mathrm{~m}$, respectively. Only layer 1 and 2 were sources for transpiration. The soil temperature at $3 \mathrm{~m}$ below the ground, the bottom boundary condition required by the OSU model to solve the thermal diffusion within the soil, is defined as the annually averaged air temperature at $10 \mathrm{~m}$ for the year 1987 , which is $13.3^{\circ} \mathrm{C}$. The FIFE data set also includes the soil temperature at 10 and $50 \mathrm{~cm}$ below the ground surface, which were used, by interpolation, to initialize soil temperatures at $2.5,50$, and $150 \mathrm{~cm}$ in the OSU model.

The FIFE data set processed by A. K. Betts and J. H. Ball (1993) provides site-averaged gravimetric soil moisture for two subsurface layers $(0-5$ and $5-10 \mathrm{~cm})$ only for the IFCs. However, Kim and Verma [1990] and Stewart and Verma [1992] provided observations on the seasonal variation of soil mois- 

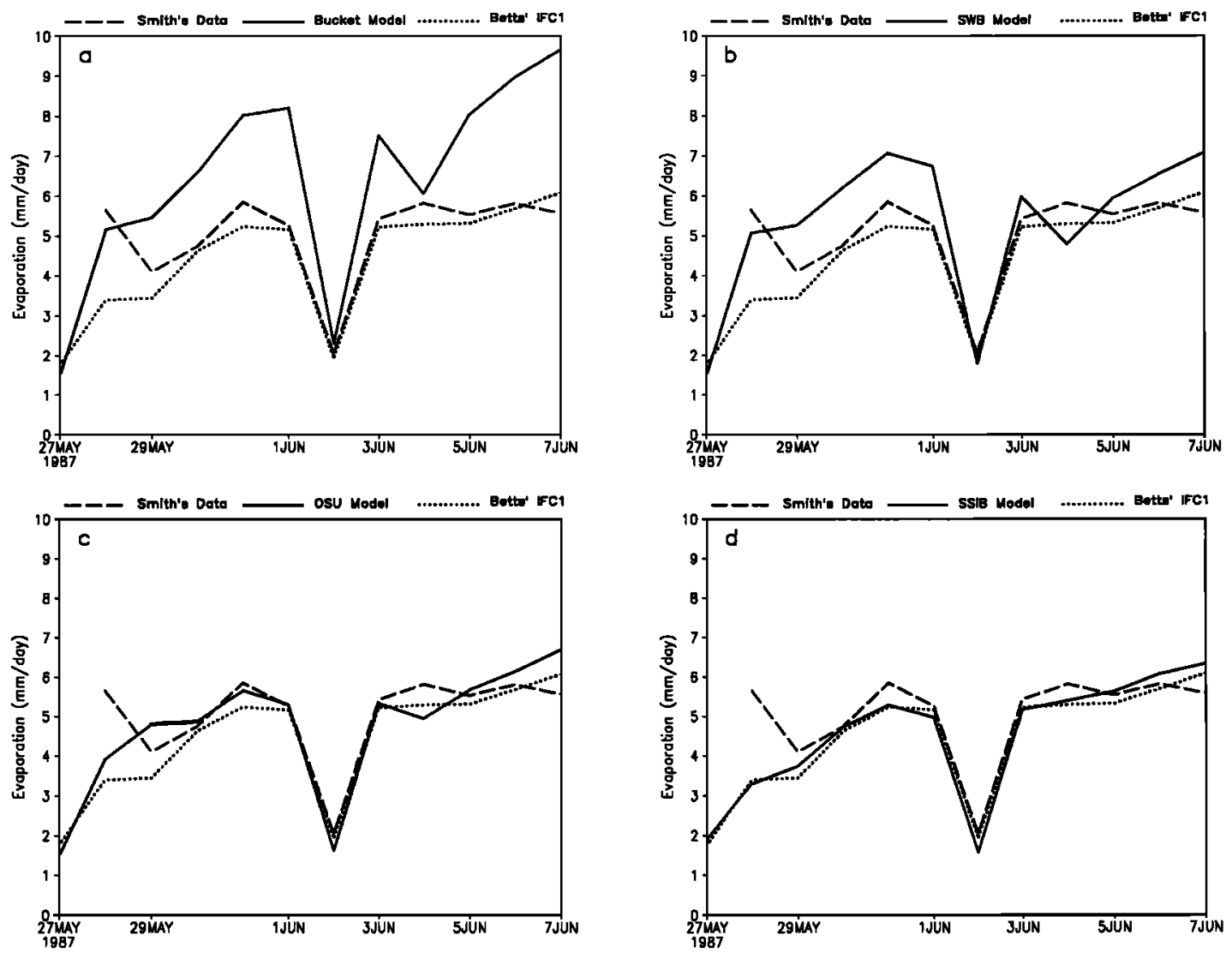

Figure 2. Comparison of daily total evaporation (in millimeters per day) between simulations and observations during IFC1: (a) bucket model, (b) SWB model, (c) OSU model, and (d) SSiB model.

ture at different depths (0-0.1 and 0-1.1 m) taken from several FIFE sites. Based on these observations, the initial OSU model volumetric soil moisture at $2.5,50$, and $150 \mathrm{~cm}$ are specified as 0.30 with corresponding initial wetness values for the three SSiB model layers.

\section{Results and Discussions}

\subsection{Hydrological Cycles}

Figures 2-4 display for three IFC periods the comparison of daily total evaporation between (1) the four model simulations, (2) A. K. Betts's and J. H. Ball's (1993) (hereinafter "Betts's") area-averaged IFC data, and (3) Smith et al.'s [1992] (hereinafter "Smith's") two-station-averaged data. Smith's evaporation is somewhat higher than Betts's IFC data, partly due to higher net radiation values over Smith's stations and partly due to wetter soil locations [Duan et al., this issue]. Nevertheless, except for several days (e.g., May 28 and 29), the evolution of Smith's evaporation is consistent with Betts's IFC evaporation. Thus Smith's data is used here for periods in between IFCs, allowing us to evaluate the 5-month simulation by these four models, as for example the daily averaged latent heat flux in Figure 5. For reference the observed daily precipitation is shown in Figure 6. In Figure 5 the evaporation reaches its maximum in June, that is, the vigorous growing season with well-stored soil moisture, and is very low in October because of canopy senescence, lower solar insolation, and dry soil.

In Figures 2-5 the bucket model overestimates the evaporation when the soil is wet, following moderate or heavy rain- fall (May 28-June 7 in Figure 2a and August 14 and 21 in Figure $4 \mathrm{a}$; see Figure 6). Because it has no canopy resistance and its $\beta$ function is linearly proportional to the soil wetness, the wet soil evaporates at nearly the potential rate $E_{p}$. Note that the maximum bucket capacity here is $270 \mathrm{~mm}$. The traditional bucket capacity of $150 \mathrm{~mm}$ [Manabe, 1969; Robock et al., 1995] would certainly make this overestimation even larger because for a given rain amount the fraction of bucket filled would be larger. Amazingly, however, because of little resistance and the deeper bucket used here, the bucket model produces relatively high evaporation during the dry period at the end of July. According to our sensitivity runs with the bucket model, a thick bucket depth (i.e., $270 \mathrm{~mm}$ in this case) significantly improved the bucket model problems of overestimating evaporation during wet periods and underestimating evaporation during dry periods experienced with the traditional bucket depth of $150 \mathrm{~mm}$ (not shown).

Although the SWB model also overestimates the evaporation during wet periods, the overestimation is less pronounced; thus the SWB model produces better results than the bucket model, except for the very dry days in July. Unlike the bucket model in which the soil evaporates at $E_{p}$ as long as soil moisture exceeds $75 \%$ of its maximum capacity, the SWB model's evaporation equals $E_{p}$ only when the surface or the deep layer is completely saturated. The shallow surface layer saturation cannot last long because of reduction in soil moisture by evaporation; the second case rarely occurs because of the large capacity $(255 \mathrm{~mm})$ in the deep soil in this simulation. To some extent the typically unsaturated deep soil acts like a sort of 

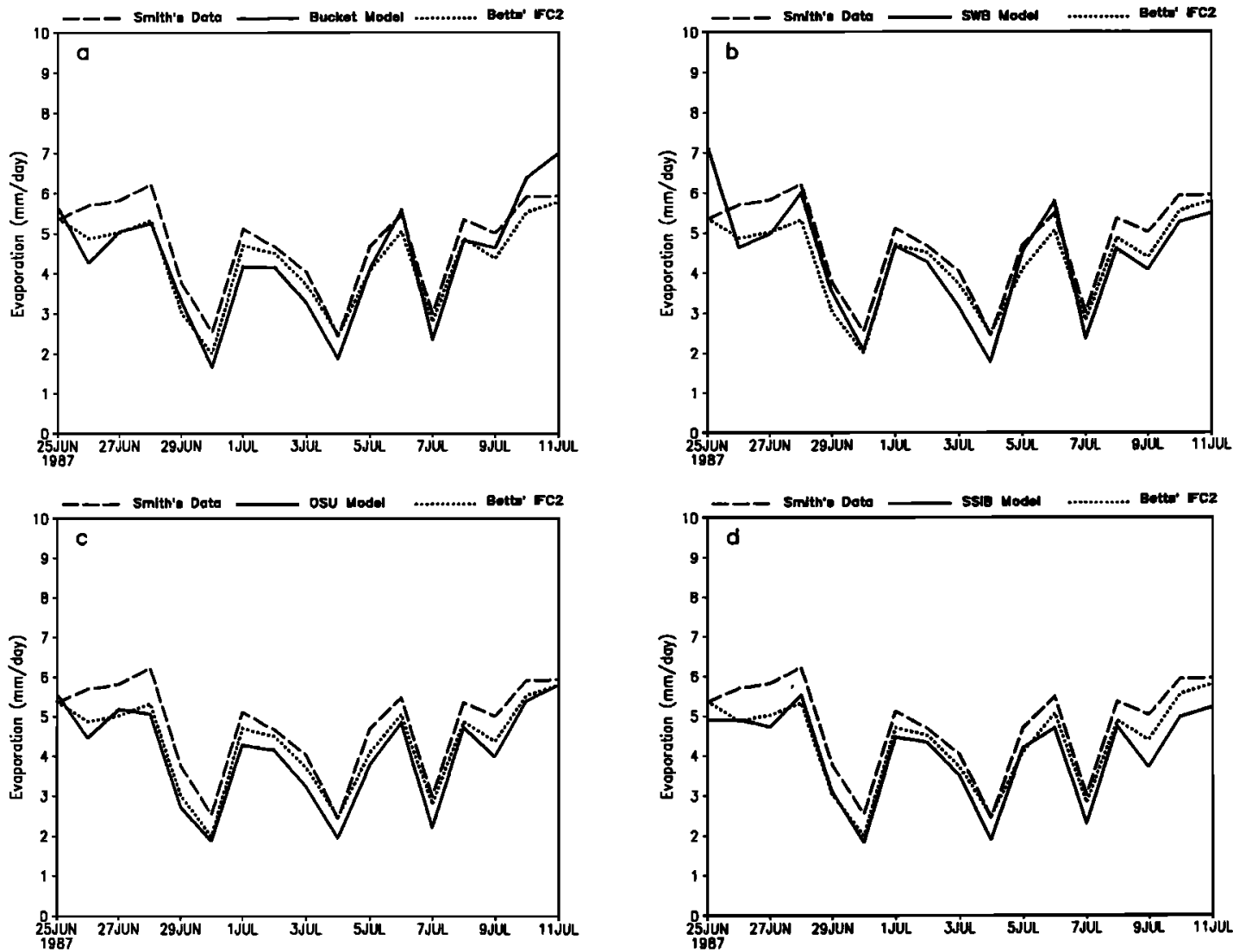

Figure 3. As in Figure 2 but for IFC2.
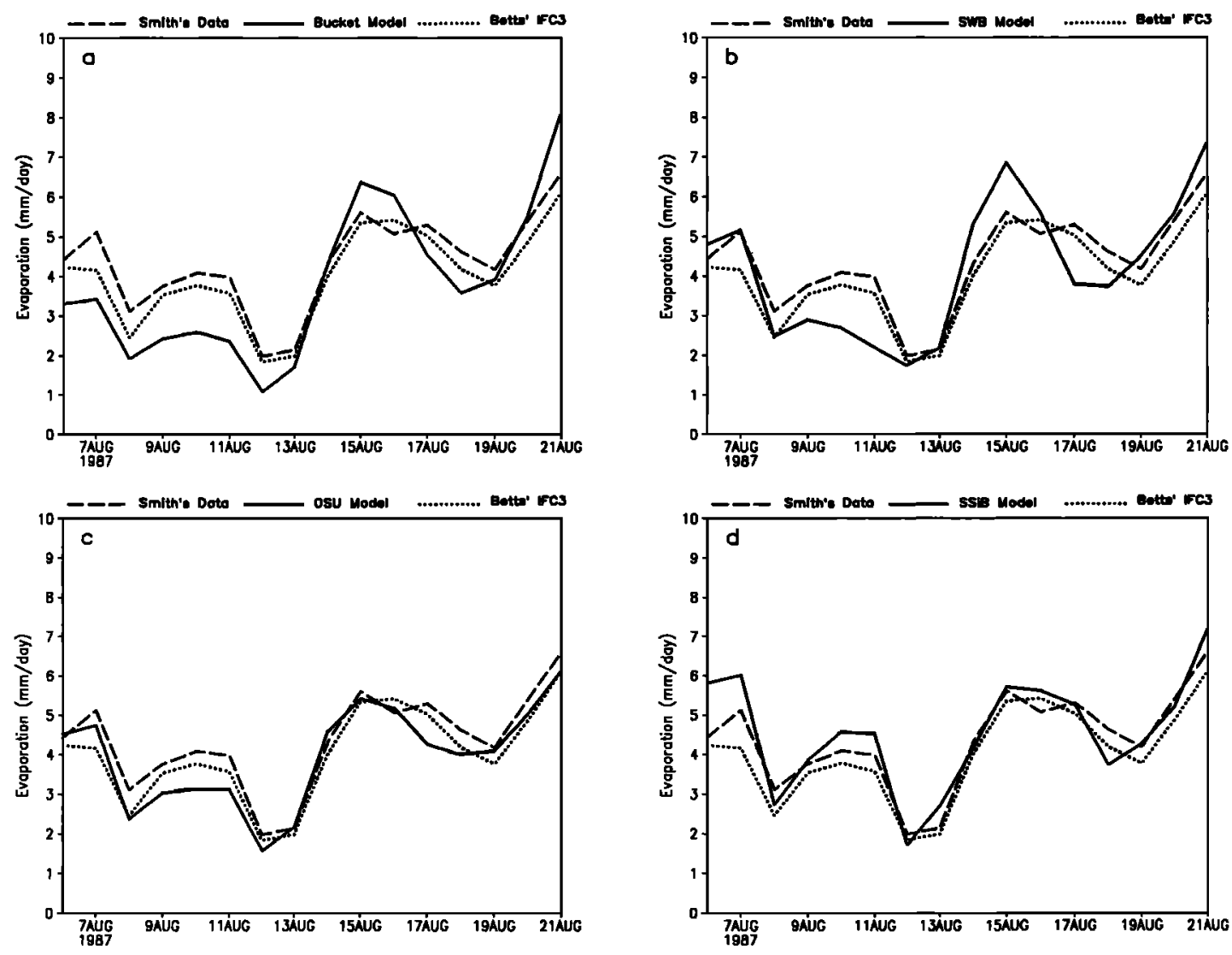

Figure 4. As in Figure 2 but for IFC3. 

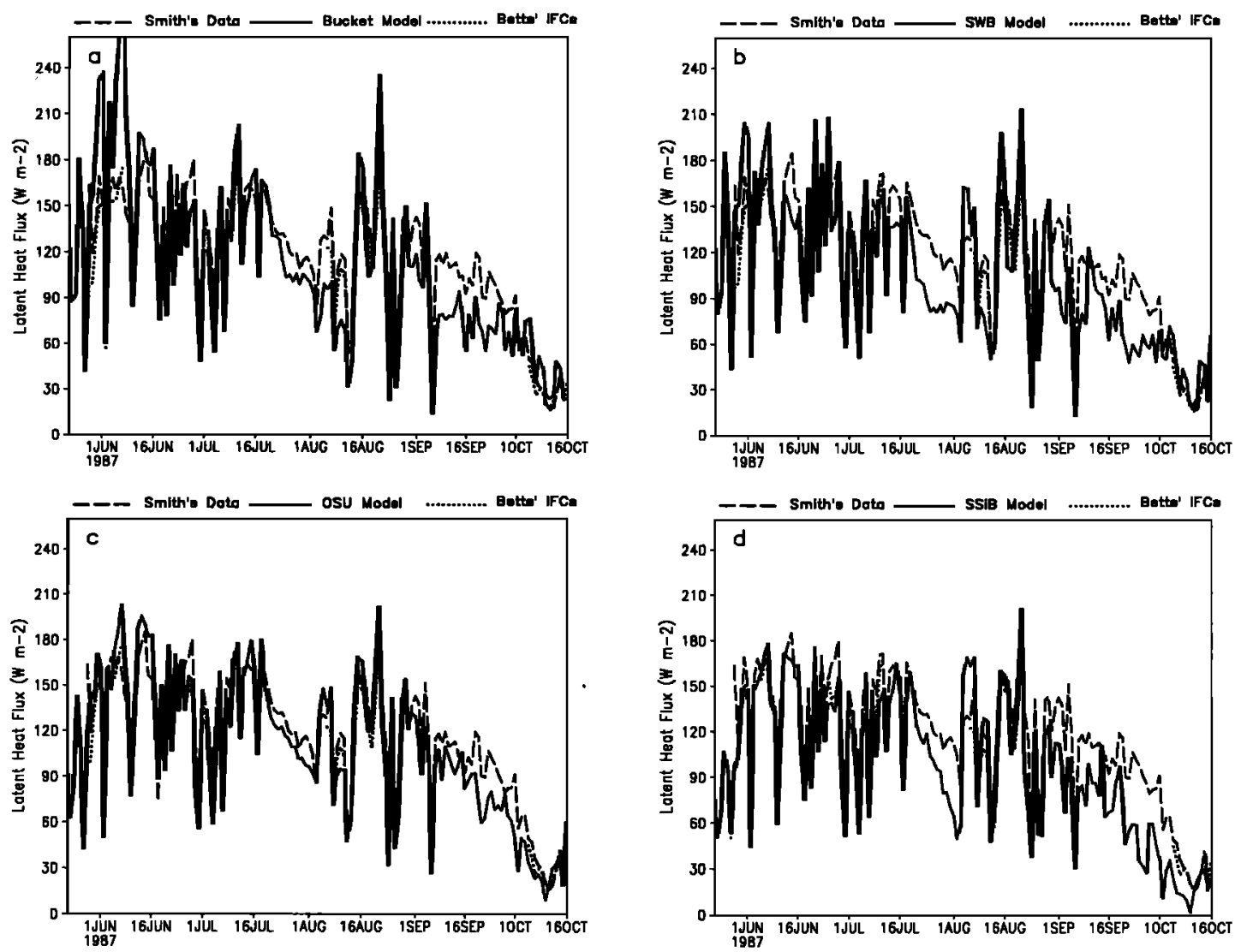

Figure 5. Comparison of daily averaged latent heat fluxes (in watts per square meter) between simulations and observations from May 22 to October 16: (a) bucket model, (b) SWB model, (c) OSU model, and (d) SSiB model.

resistance and efficiently prevents the overestimation of evaporation in the SWB model during wet periods.

The SWB model, however, underestimates the evaporation during nonwet periods, particularly when its surface layer becomes dry. Several factors can explain the low evaporation from the deep soil, which is the major contributor to the total evaporation when the surface layer is dry. For example, the depth of the surface layer and the deep layer may not be appropriate for the FIFE site; the same may be true for the

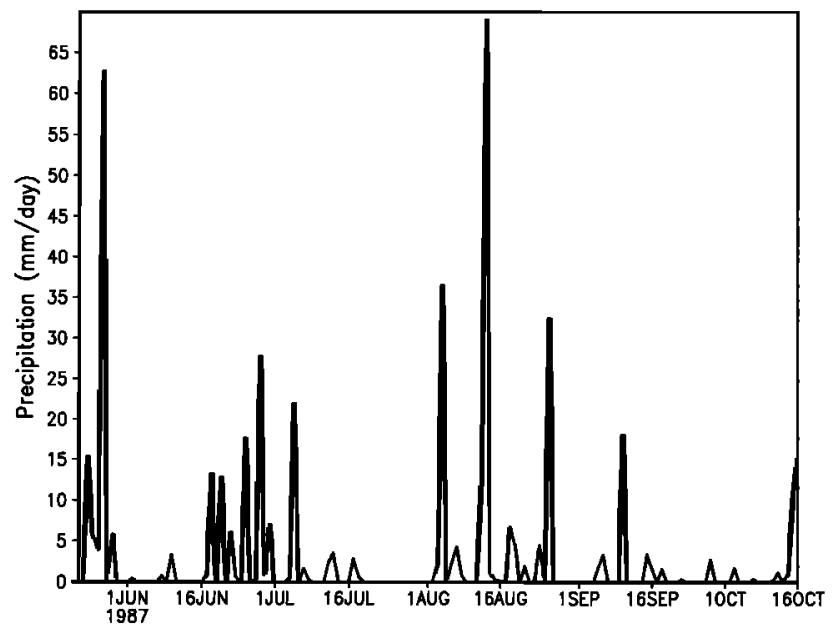

Figure 6. Daily total precipitation (in millimeters per day). way in which the SWB model weights the evaporation between the surface and the deep layer. Although the deep layer in the SWB model is intended for implicitly representing vegetation, the process of uptaking water from the deep soil by vegetation during the relatively dry period may not be suitably treated. For this reason, in a sensitivity test, we explicitly included the canopy resistance of (13) in the SWB model. As we will see later in section 4.3 , the inclusion of the canopy resistance improved the evaporation calculation substantially.

Overall, the evaporation obtained from the OSU model and the SSiB model, both accounting for the canopy resistance explicitly, was in good agreement with IFC observations and Smith's data. In the wetter IFC1 the SSiB model produced better evaporation than the OSU model, which slightly overestimated the evaporation. In the drier IFC3 and IFC4, the OSU model obtained better evaporation than the SSiB model. As can be seen in Figure 5, during relatively dry periods (i.e., at the end of July, in September, and in October; see soil moisture in Figure 8), latent heat fluxes obtained in the OSU model are closer to Smith's data than are the SSiB simulations. As compared to the bucket model the inclusion of canopy resistance in the OSU and SSiB model can effectively avoid the overestimation of evaporation in wet periods and then release this water storage in follow-on dry periods, which is critical for the simulation of longer seasonal evolution of evaporation. In section 4.3 we will discuss in more detail the important role of canopy resistance in the surface evaporation formulation.

We turn our attention now to diurnal behavior. Figure 7 

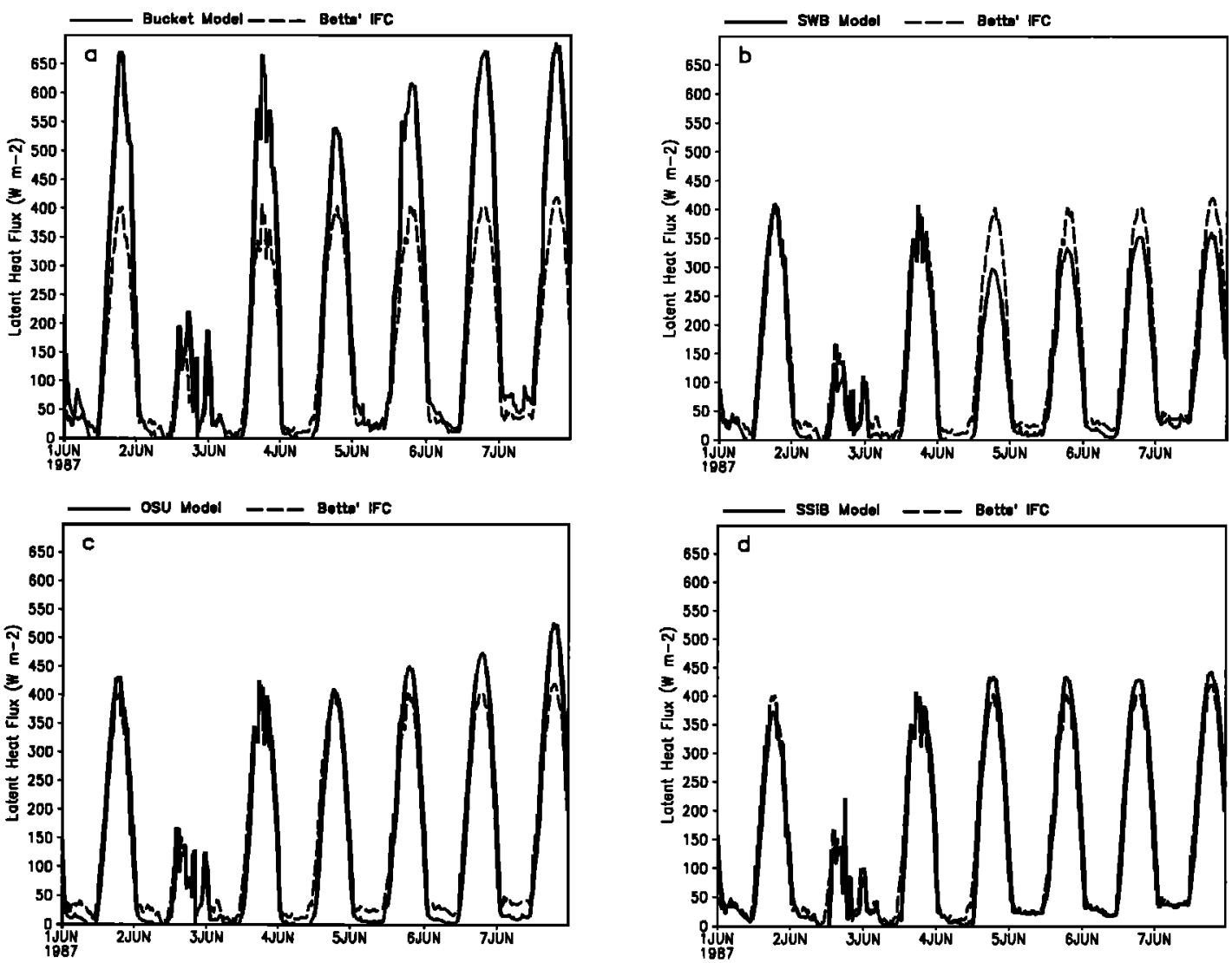

Figure 7. Comparison of diurnal variation of latent heat fluxes (in watts per square meter) between simulations and observations for June 1-7: (a) bucket model, (b) SWB model, (c) OSU model, and (d) SSiB model.

illustrates an example of the comparison between observed and simulated diurnal variation of latent heat fluxes for a relatively wet period in June. Not surprisingly, the bucket model produced the peak noontime latent heat flux, almost double the observed value. The SWB model, in spite of its relatively simple treatment of evaporation, can produce good results, as shown. The OSU model and the SSiB model simulate correctly the diurnal cycle, though the OSU model overestimates the maximum latent heat flux by about $100 \mathrm{~W} \mathrm{~m}^{-2}$ on June 7. The OSU model, however, produced better diurnal cycle behavior in relatively dry periods in July and in October (not shown here, but expected from August 1 and October 1 results in Figures $5 c$ and $5 d$ ).

We next consider the evolution of soil moisture in Figure 8. Since the SWB model uses the soil moisture deficit $D$ as a prognostic variable, we must convert it into volumetric soil moisture for model intercomparison. To do so we use $\Theta=$ $\Theta_{w}+\left(\Theta_{\text {ref }}-\Theta_{w}\right) \times\left(D_{\max }-D\right) / D_{\max }\left(\Theta_{w}\right.$, wilting point; $\Theta_{\text {ref }}$, field capacity). A similar conversion [Robock et al., 1995] was applied to the bucket model soil moisture. Qualitatively, the evolution of the soil moisture in the deep layer among these four models is similar (Figure 8). Owing to its overestimating evaporation during wet periods, the bucket model was the driest one among them. The SWB model surface moisture changed more dramatically than the OSU and SSiB model surface moisture, because the storage of precipitation and its reevaporation with little resistance occurred mostly in the surface layer.
In the SSiB model, water from the more moist third layer diffused to the second layer more efficiently than in the OSU model, which employs an explicit diffusion equation. This is one major reason that the second layer in the SSiB model is, on the whole, more moist than the OSU model second layer. The SSiB model second layer soil moisture agrees well with the two-site observation of vertically averaged soil moisture (0-1.1 m) shown by Stewart and Verma [1992]. Because the areaaveraged observations in soil moisture at $52.5 \mathrm{~cm}$ (the OSU model predictive level) are not available, it is difficult to validate the OSU-simulated soil moisture at this time. Nevertheless, the OSU second layer soil moisture is, in general, in good agreement with the observation of Stewart and Verma [1992].

Between the SSiB and OSU models, the soil in the OSU model had the driest soil $(\Theta=0.20$ at $52.5 \mathrm{~cm})$ on July 31 because of little precipitation in the preceding 3 weeks (Figure 6). This is very close to the observed soil moisture profile on July 31 given by Kim and Verma [1990], in which $\Theta=0.21$ at $52.5 \mathrm{~cm}$. It is interesting to note that even though the second layer in the SSiB model was wetter than that in the OSU model for July 16-30 and for September 16-October 16 (Figure 8), the SSiB model produced less evaporation than the OSU model for these periods. This implies that the SSiB model has an overall larger resistance than the OSU model. Additionally, Betts et al. [1993], comparing the European Centre for Medium-Range Weather Forecasts (ECMWF) operational weather forecast model simulations with FIFE data, indicated that there was nearly zero surface evaporation in that model from 

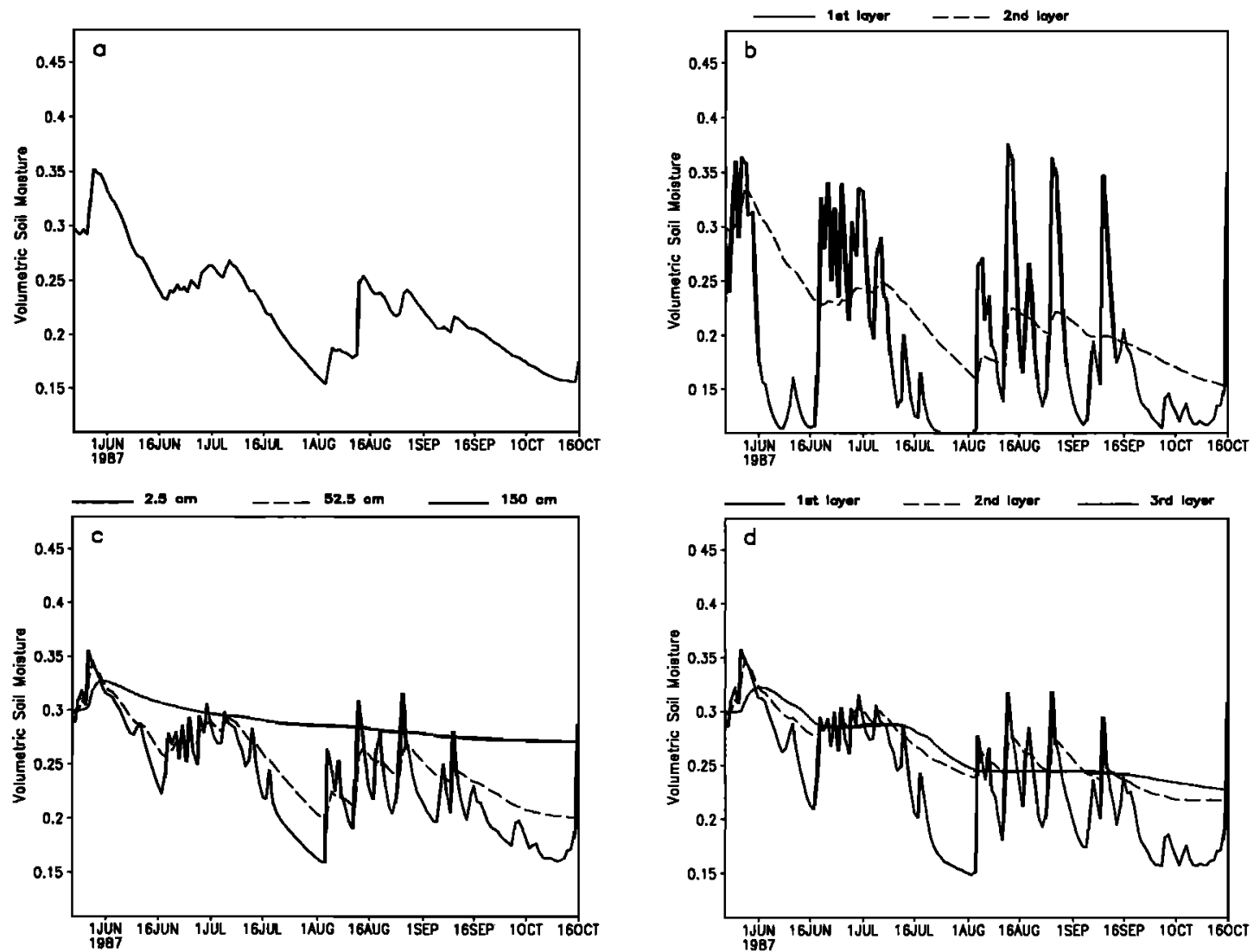

Figure 8. Seasonal evolution of daily averaged volumetric soil moisture simulated by four surface models: (a) bucket, (b) SWB, (c) OSU, and (d) SSiB.

October 5 to 13 because the model soil moisture specified in the "restoring" layer for October was very dry. It seems common that land surface models tend to underestimate the evaporation during very dry periods, because of large resistance, for example, when the grid cell mean soil moisture is close to traditionally used wilting points. The broader soil moisture stress function in Figure 1, conceptually based on subgrid variability as discussed earlier, contributed to reduce the canopy resistance in the OSU model and maintain higher evaporation rates in the latter half of July.

Finally, we consider the runoff component of the hydrology. Not surprisingly, these models produced very different runoff (Figure 9). As expected, the bucket model generated the least runoff among them, in fact no runoff at all in this simulation, since the condition for runoff, namely a full bucket, never occurred in this 5-month test with a bucket capacity of $270 \mathrm{~mm}$. Our sensitivity study also showed that even with a shallow bucket depth (i.e., $150 \mathrm{~mm}$ ), the bucket model only generated $19 \mathrm{~mm}$ of runoff on May 27.

As described by Mahrt and Pan [1984], the maximum infiltration rate in the OSU model is traditionally parameterized in terms of the estimated water flux by both diffusion and conduction at the surface under conditions of saturation, which acts to generate surface runoff only during extremely heavy rainfall. Indeed, in our sensitivity test (not shown here), the simulation with this original OSU model infiltration treatment produced less than $10 \mathrm{~mm}$ runoff for the total 5-month period. As an attempt to improve the surface runoff calculation in the OSU model, we replaced the formulation with the SWB scheme of (22), which accounts for the subgrid variability in precipitation and soil moisture.

The results are shown in Figure 9 in which the OSU and SWB models now have similar runoff responses. A large portion of the runoff produced by the models on May 27 came from subsurface drainage (base flow). On August 13 the surface runoff was the dominant mechanism in the SWB model and in the OSU model, while the surface runoff and subsurface drainage contributed almost equally to the total runoff in the SSiB model. Unfortunately, there are no suitable runoff observations over the entire FIFE area to verify these simulations. As runoff can affect the evolution of soil moisture and therefore alter subsequent evaporation, especially on longer annual timescales, the runoff calculations must be validated further in separate, longer-term studies against stream flow and runoff data available over other basins. One such study is that of Schaake et al. [this issue], which examines the bucket, SWB, and OSU models over three river basins.

\subsection{Soil-Atmosphere Thermodynamics}

Smith's two-station-averaged sensible heat fluxes are, except in October, also slightly higher than Betts's area-averaged sensible heat fluxes (Figure 10), as in the case of latent heat fluxes. From May 27 to June 7 the bucket model produced unrealistically large negative sensible heat fluxes compared to observations (see Figure 10a), owing to its overestimating evaporation. The SWB model transferred too much sensible heat from the surface to the atmosphere in June and at the end of July, because it underestimated the evaporation over these periods. 

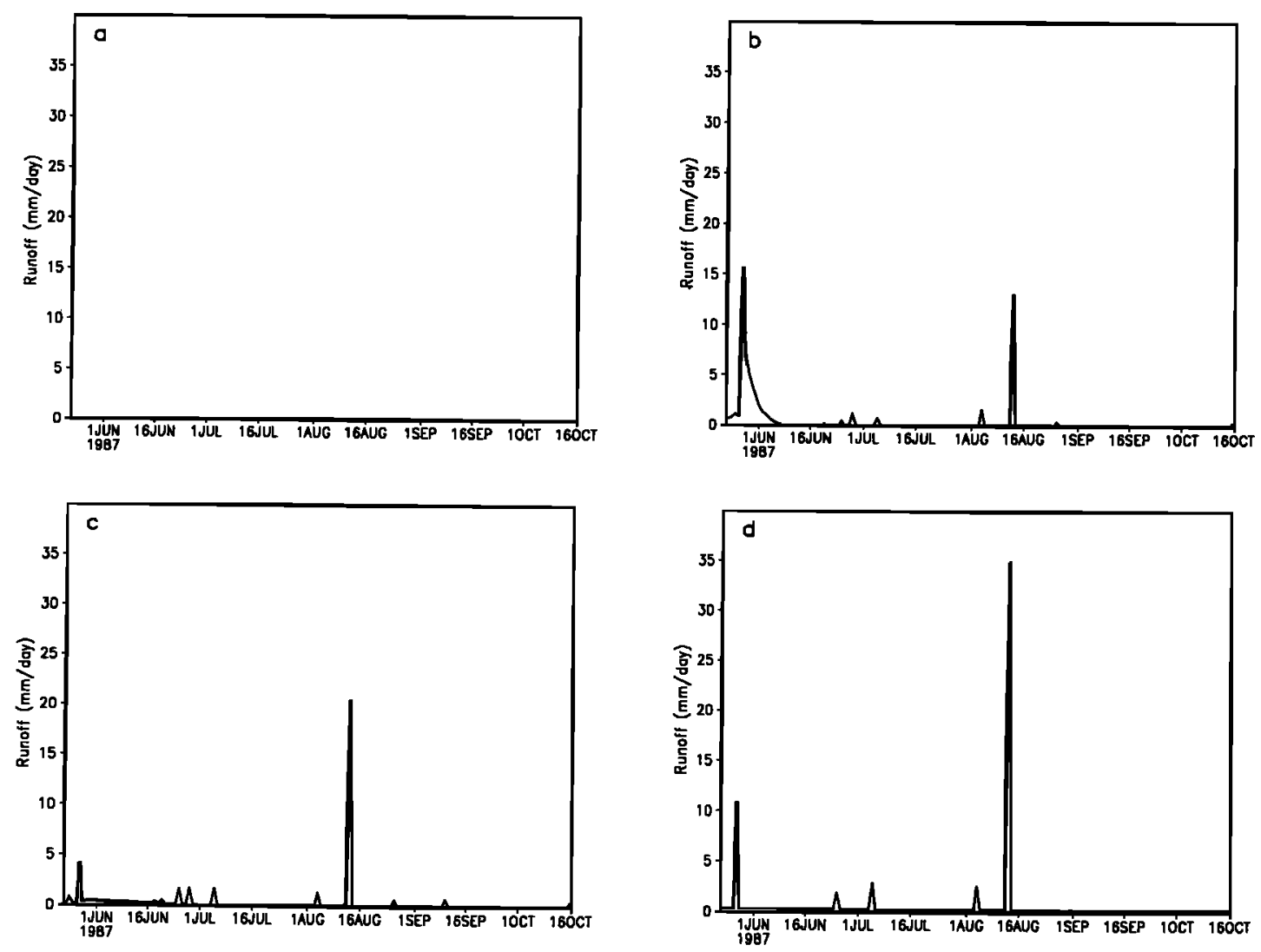

Figure 9. The daily total runoff (in millimeters per day) simulated by four surface models: (a) bucket, (b) SWB, (c) OSU, and (d) SSiB.

On the whole, the OSU model and the SSiB model performed well in simulating the seasonal variation of sensible heat fluxes. Nevertheless, the OSU model sensible heat fluxes at the end of July and in September were closer to Smith's observations than the SSiB model results.

As we explained in section 3.1 the bucket model and the SWB model used the same thermodynamics, that is, the OSU soil thermodynamics. The simulated soil thermodynamical variables such as soil heat fluxes, soil temperature, and surface skin temperature can be slightly different in these three models. This difference, however, is merely the consequence of the difference in soil moisture among these models. Therefore, in the following discussions, we focus on the comparison of thermodynamics between the OSU model and the SSiB model. As we indicated in section 3 , the OSU model solves the thermal diffusion equation in the soil explicitly, but the SSiB model is based on the force restore method.

In general, the OSU soil heat fluxes were lower than the SSiB fluxes and closer to FIFE observations (see Figure 11). Even though the SSiB model captured the pattern of the evolution of observed soil heat fluxes, it generated overly large negative fluxes throughout August and October. The SSiB soil heat fluxes during the periods June 4-16 and July 16-31 are higher than the OSU fluxes, but agree better with observations.

It is especially interesting to compare the skin temperature simulations of the OSU and SSiB models. The observed dailyaveraged surface skin temperature increases from May until it reaches a maximum value at the end of July (Figure 12) due to large incoming radiation and less evaporation. Both the OSU model and the SSiB model predicted the daily-averaged sur- face skin temperature amazingly well. Except for several days, for example, June 13-15, 17-21, September 14, etc., the difference between simulations and observations was smaller than $1^{\circ} \mathrm{C}$. The daily-averaged surface skin temperature in the SSiB model was, in general, closer to observations than that in the OSU model, although the difference between the two models was small.

We recall that the OSU surface skin temperature is a single energy balance temperature of the combined bare soil and vegetated surface. By contrast, the $\mathrm{SSiB}$ model calculates the skin temperature separately for the ground surface and the vegetation canopy temperature and then computes a weighted average. To predict the canopy temperature, the SSiB model employs a comprehensive biophysical and radiative transfer scheme, which increases the level of complexity in the model. This complexity may help the SSiB model produce a better surface skin temperature, in Figure 11, for the driest period in July. Another important reason, as demonstrated by the higher $\mathrm{SSiB}$ soil heat fluxes in Figure 11, is that the force restore method used in the SSiB model seems to more quickly transfer the heat from the surface to the deep layer.

However, relative success in daily-mean temperatures can mask problems with the amplitude and phase of the diurnal cycle. Figure 13 compares the diurnal cycle of surface skin temperature for several days during one wet period (June) and two dry periods (July and October). The OSU model, in general, was able to capture remarkably the nighttime minimum skin temperature, but it tended to produce higher noontime maximum temperatures than observations, hence the warm bias noted in the daily-mean skin temperature in Figure 12. In 

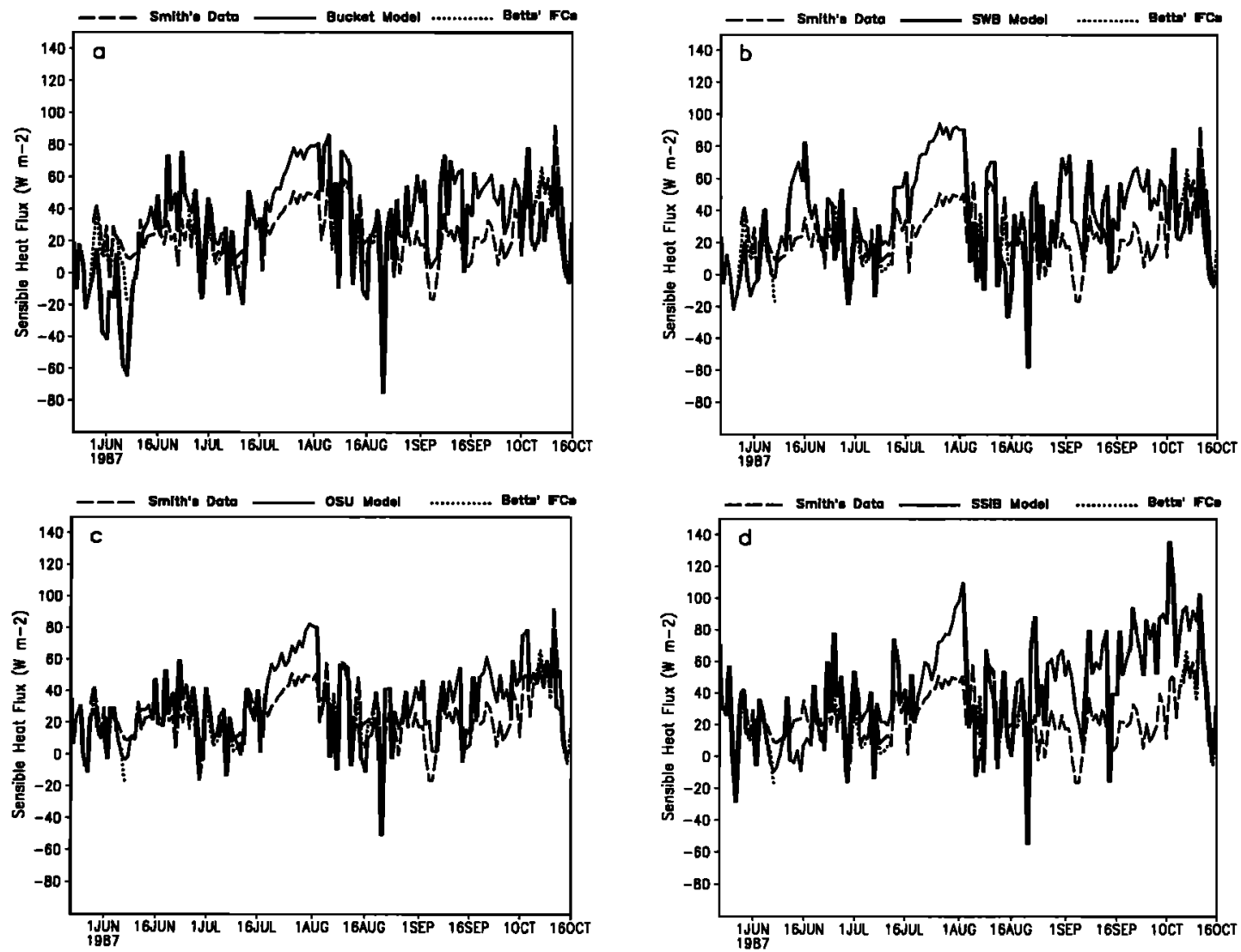

Figure 10. As in Figure 5 but for sensible heat fluxes.

particular, the difference of maximum surface skin temperature between OSU simulations and observations could be as high as $5^{\circ} \mathrm{C}$ in late July when the soil is very dry. This was reflected in the positive OSU sensible heat flux bias in late July in Figure 10c. Since the surface skin temperature may have important impacts on the development of model forecast convective systems in the afternoon as shown by Anthes [1984] and Chen and Avissar [1994b], among many others, this overestimation of maximum skin temperature in the OSU model requires further investigation. Figures $5 \mathrm{c}, 10 \mathrm{c}$, and 11a, taken together for late July, clearly indicate that the latter OSU high-temperature bias originates partly from underestimated soil heat flux. This shortfall is further evident in a $3^{\circ} \mathrm{C}$ soil temperature cold bias at $50 \mathrm{~cm}$ in the OSU model compared to FIFE observations in late July (not shown). Whether this cold soil temperature bias is due to truncation error (thick layers and poor resolution) or incorrect soil thermal properties (as demonstrated by recent sensitivity studies, e.g., that of Cuenca et al. [this issue] is yet to be determined.

The SSiB model shows two diurnal biases in Figure 13: a low bias in noontime maximum skin temperature and a high bias in nighttime minimum skin temperature. These two biases tended to cancel out and give rather good (but misleading) daily-mean values in Figure 12. Deardorf [1978] compared the prediction of surface skin temperature by a 10-layer soil model and the force restore method, along with four other methods. He pointed out that the force restore method underestimated the surface skin temperature. The SSiB model indeed simulates a smaller diurnal amplitude of skin temperature than the OSU model, partly since the soil heat flux in SSiB is so efficient, relative to that in the OSU model, as evident by comparing June and July in Figures 11a and 11b.

\subsection{Sensitivity Experiments With SWB and OSU Model}

4.3.1. OSU model without canopy resistance. To demonstrate the role of a time-dependent canopy resistance in land surface evaporation, we present in Figure 14, for comparison with Figure $5 c$, the daily-averaged latent heat fluxes calculated by the OSU model without canopy resistance. Here, we replaced (13) by (12) (with $P_{c}=0.7$ ) which includes only the soil moisture stress function. In so doing, the total number of parameters is reduced from 15 to 10 (see Table 3). Assuming for discussion that $\sigma_{f}$ is 1 in (11), $P_{c}$ is basically the ratio between actual evaporation and potential evaporation, thus indicating the canopy's ability to evaporate. This plant coefficient or "crop coefficient" approach has long been applied in agriculture to estimate the irrigation amount for large fields.

With only the soil moisture stress effect on canopy resistance, the OSU model, like the bucket model, overestimated the evaporation during wet periods (in May, early June, midJuly, and mid-August). The loss of large quantities of evaporated water during these wet periods reduced the soil moisture significantly. As a result, this subsequently limited the model's evaporation in follow-on drier periods, thereby resulting in lower evaporation in days following the above wet days, that is, mid-June, end of July, end of August, and early September. As compared with Figure 5c, the evaporation during these relatively dry periods was much lower than the simulation with canopy resistance. Overall, the model with a constant $P_{c}$ gen- 

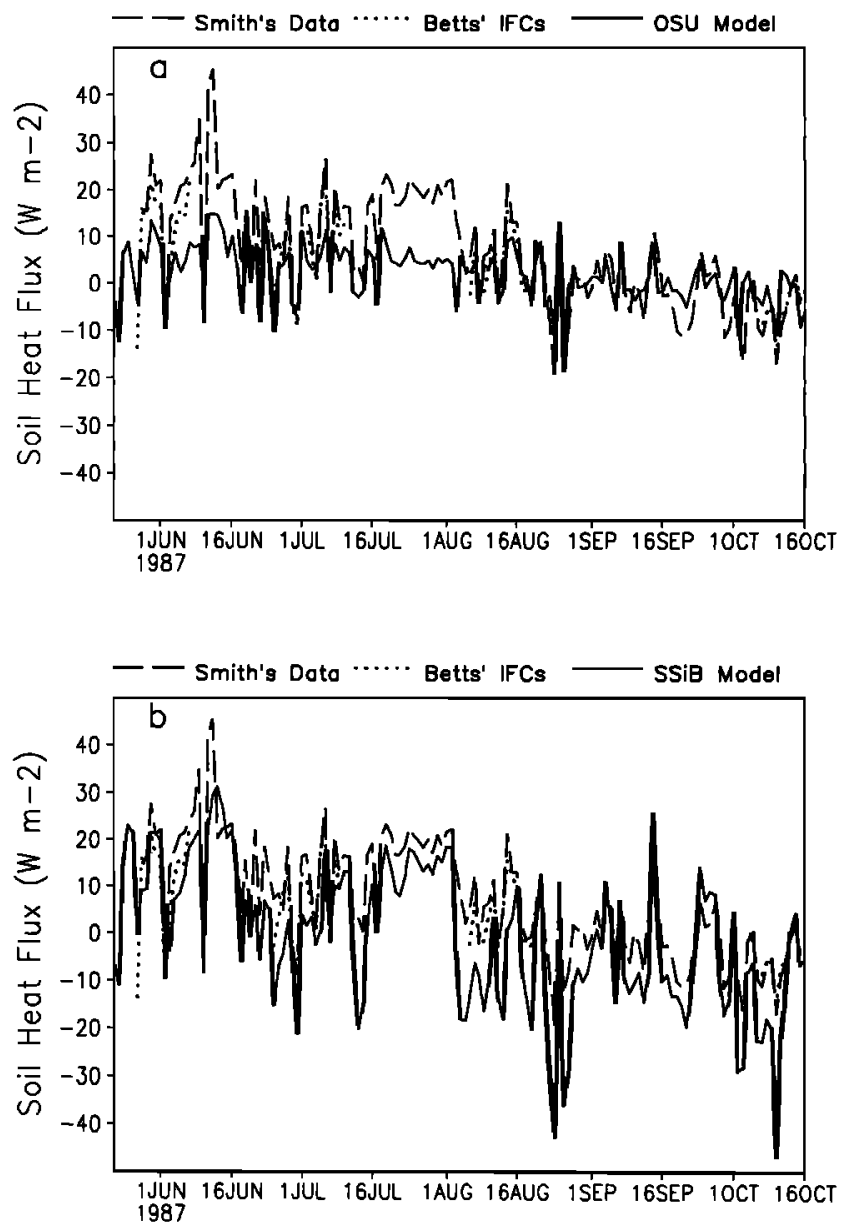

Figure 11. Comparison of daily averaged soil heat fluxes (in watts per square meter) between simulations and observations from May 22 to October 16: (a) OSU model and (b) SSiB model.

erated larger interweekly oscillations of evaporation than either observations or the model with canopy resistance.

In companion sensitivity tests, we tried several alternative values of $P_{c}$ ranging from 0.5 to 0.9 . Although different values of $P_{c}$ improved the results during some particular periods, it was not able to alter the general pattern of overestimation of evaporation in wet periods and the underestimation of evaporation in relatively drier periods.

4.3.2. SWB model with canopy resistance. To include canopy resistance in the SWB model, we replace (20) and (21), which calculate the evaporation from the upper and bottom layer in the SWB model, with

$$
\begin{gathered}
E u=\sigma_{f} E p\left(1-\frac{D(1)}{D 1_{\max }}\right)^{0.5} \\
E b=\left(1-\sigma_{f}\right) E p\left[1-\left(1-\frac{D(1)}{D 1_{\max }}\right)^{0.5}\right]\left(1-\frac{D(2)}{D 2_{\max }}\right)
\end{gathered}
$$

where $\sigma_{f}$ is, again, the fraction of green vegetation. To represent canopy evapotranspiration, a new sink term $E_{t}$ is added to the bottom layer (i.e., on the right of (19))

$$
E_{l}=\sigma_{f} E p B_{c}\left[1-\left(1-\frac{D(1)}{D 1_{\max }}\right)^{0.5}\right]
$$

where $B_{c}$ is the canopy resistance and calculated from (13) and (14). In considering canopy resistance this version of SWB model has 14 parameters, almost the same complexity as the OSU model (Table 3). Compared to the OSU evaporation formulation expressed in (8), (9), and (11), we see that this new set of equations for the SWB model intends to represent (conceptually but not equivalently) the direct evaporation from bare soil, $E b$, the reevaporation of the precipitation intercepted by the canopy, $E u$, and canopy evapotranspiration, $E_{t}$.

Figure 15 provides the daily-mean latent heat fluxes obtained with this new evaporation formulation. As compared to Figure $5 b$, this model effectively reduces the overestimation of evaporation from the end of May to early June and at the end of June. Also, the new model remedies the underestimation of evaporation by the original model in mid-June, the middle and end of July, and August 9-11. This model, however, evaporates more during June 5-7 than the original model. This high evaporation was due to a low canopy resistance, which appeared in the OSU model simulation as well (Figure 5c). On the whole, compared to the original SWB model simulations, the model including canopy resistance produces a smaller seasonal cycle of evaporation, which is closer to the FIFE observations.

4.3.3. Discussion. From the above studies it is clear that a sound surface model should be able to recharge the soil moisture during the wet periods, reasonably retain it, and release it later in the dry periods. We believe that the canopy resistance is an indispensable factor to prevent the overestimation of evaporation during wet seasons (in contrast to the bucket model). Consequently, the water retained in the deep soil can be drawn up from the root zone in dry periods, which is demonstrated by the SWB model with canopy resistance. By embracing a formulation for canopy resistance, a relatively simple model such as the OSU model was able to correctly simulate the diurnal and seasonal cycle of evaporation, with acceptable performance similar to the more sophisticated SSiB model. From these tests it seems that in order to obtain the evaporation reasonably correctly, a surface model needs about 12-15 parameters (see Table 3).

For a proper assessment of diurnal and seasonal variation in canopy resistance it is important to parameterize the influence

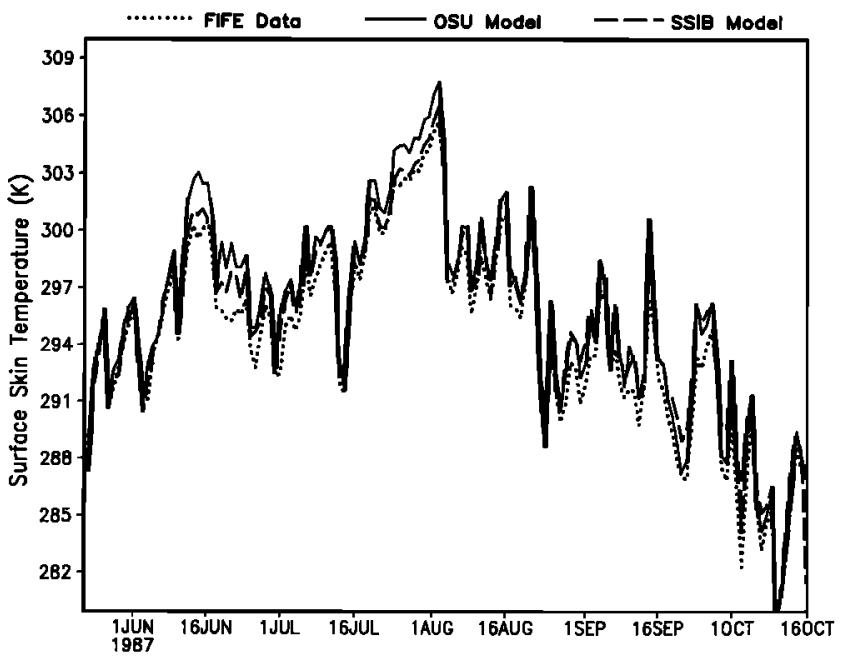

Figure 12. Comparison of daily averaged surface skin temperature between the OSU model and SSiB model simulations and FIFE observations. 


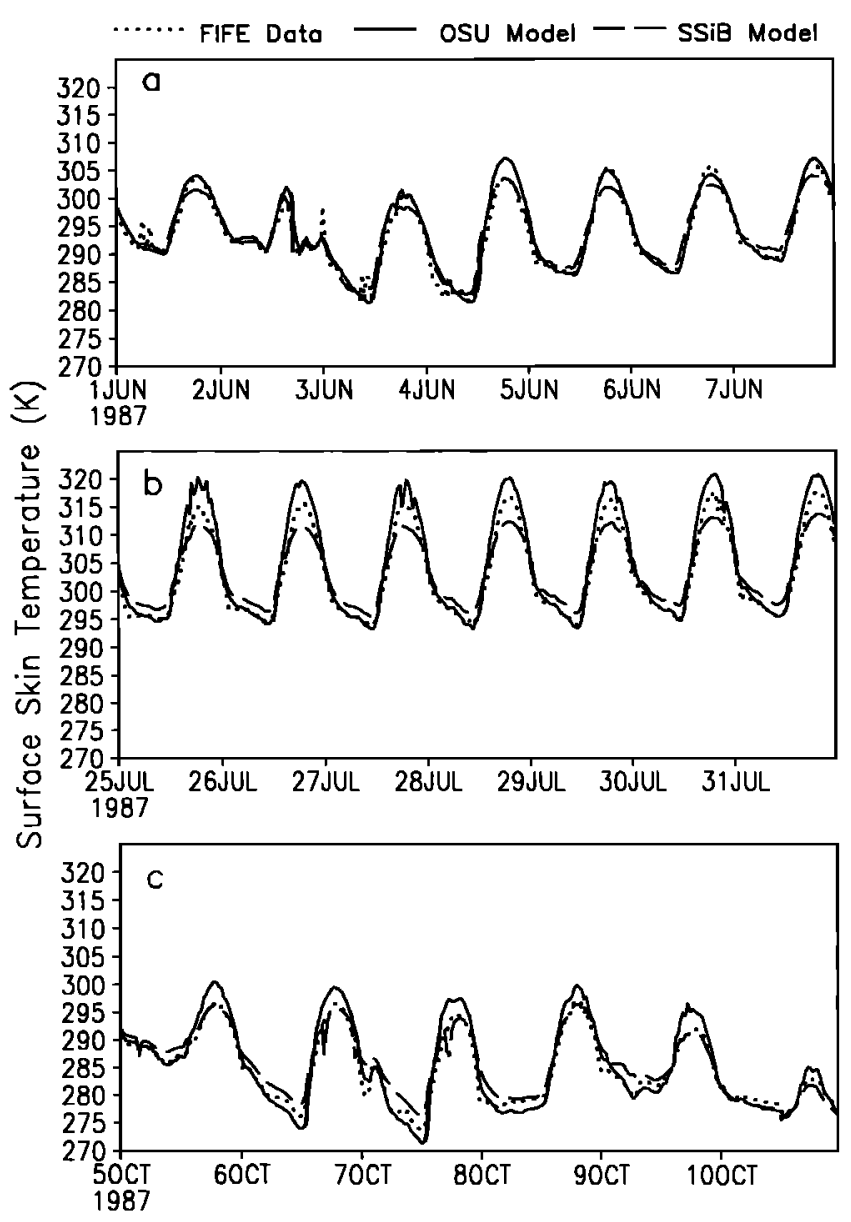

Figure 13. Comparison of diurnal variation of surface skin temperature between the OSU and SSiB model simulations and FIFE observations: (a) June 1-7, (b) July 25-31, and (c) October 5-10.

of both the atmosphere and the soil on the canopy resistance. For example, considering the subgrid-scale variability of soil moisture in a simple way, the nonlinear soil moisture stress function (Figure 1) used in the OSU model significantly improved the evaporation during dry periods, in particular at the end of July and in October. Even within the rather small $15 \mathrm{~km}$ $\times 15 \mathrm{~km}$ FIFE area, the subgrid-scale variability is substantial [Duan et al., this issue]. Stewart and Verma [1992] indicated that the soil moisture stress function for one FIFE site was $16 \%$ higher than that of a second FIFE site, when there was $50 \%$ of the extractable soil moisture still available. Our sensitivity experiments with the OSU model (not shown) also indicate that the results are sensitive to the inclusion of the vapor pressure deficit stress. This is supported by FIFE observations. For example, Kim and Verma [1990] observed that the middayaveraged latent heat flux on July 11 was $402 \mathrm{~W} \mathrm{~m}^{-2}$, about twice the value on July $30\left(208 \mathrm{~W} \mathrm{~m}^{-2}\right)$. Although the potential evaporation was much higher on July 30 , the evaporation was substantially reduced, because of partial stomatal closure. According to them, this was likely due to not only higher soil moisture stress, but also higher vapor pressure deficit stress; the vapor pressure deficit for July 30 was about 2.4 times higher than that for July 11.

Furthermore, including an explicit treatment of canopy resistance in NWP models implies that we need to specify more complete information on the vegetation state, including the spatial distribution of vegetation type and its temporal variation in greenness. The specification of the vegetation state over continental scales should rely on recent improvements in remote sensing techniques. For example, our sensitivity experiments (not included) showed that using the seasonal cycle of vegetation greenness fraction (Table 4), derived from a 5-year climatology of normalized difference vegetation indexes (NDVI) [Gutman et al., 1995], yielded better evaporation than using a time-fixed value, particularly in October following vegetation senescence.

\section{Conclusions}

We have intercompared the one-dimensional 5-month simulations of four land surface models, embodying very different treatments of the hydrological cycle, with observations spanning from early summer to early fall of 1987 over the $15 \mathrm{~km} \times$ $15 \mathrm{~km}$ FIFE area in northeast Kansas. This study demonstrated that using long-term, area-averaged atmospheric forcing conditions and surface flux data to drive and verify land surface models is very beneficial to understanding their performance and limitations. Such models have been designed for different temporal and spatial scales, but previously tested mostly by short-term, local measurements.

The traditional bucket model failed to correctly simulate the evaporation for wet and dry soils; in particular, it considerably overestimated evaporation in wet periods because of its low resistance. The SWB model, despite its relatively simple evaporation formulation, simulated the observed evaporation for wet periods well because its second layer, acting as a resistance factor, prevented the overestimation of evaporation. It, however, displayed some deficiencies during dry periods. The OSU model and the SSiB model, both accounting for canopy resistance explicitly, reasonably simulated the diurnal and seasonal variation of evaporation observed during four IFC periods. Overall, the OSU (SSiB) model simulated evaporation better during dry (wet) periods. Notably, the SSiB model produced less evaporation than the OSU model (and observations) during dry periods despite having higher soil moisture during these periods. This implies that on the whole, the SSiB model

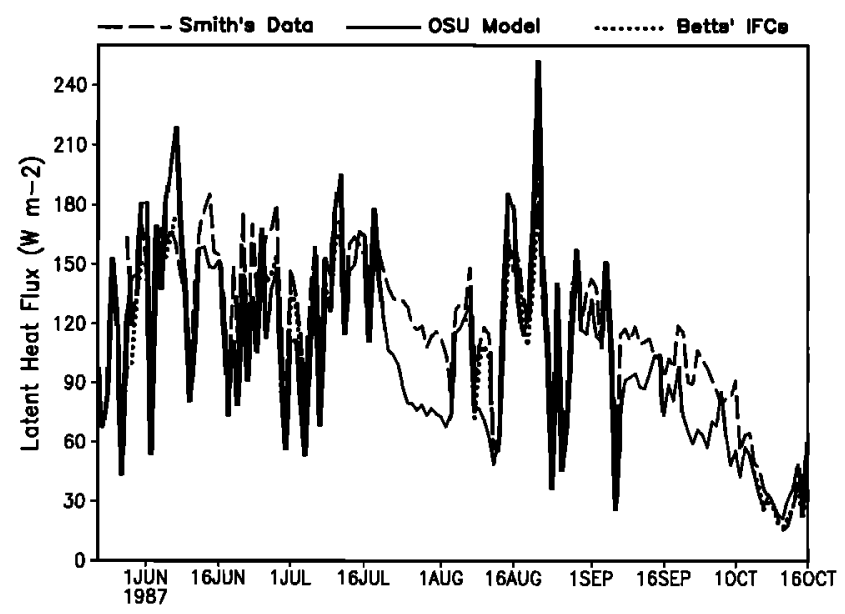

Figure 14. Comparison of daily averaged latent heat fluxes (in watts per square meter) between simulations by the OSU model with a less complex canopy resistance and observations from May 22 to October 16 (compare to Figure 5c). 


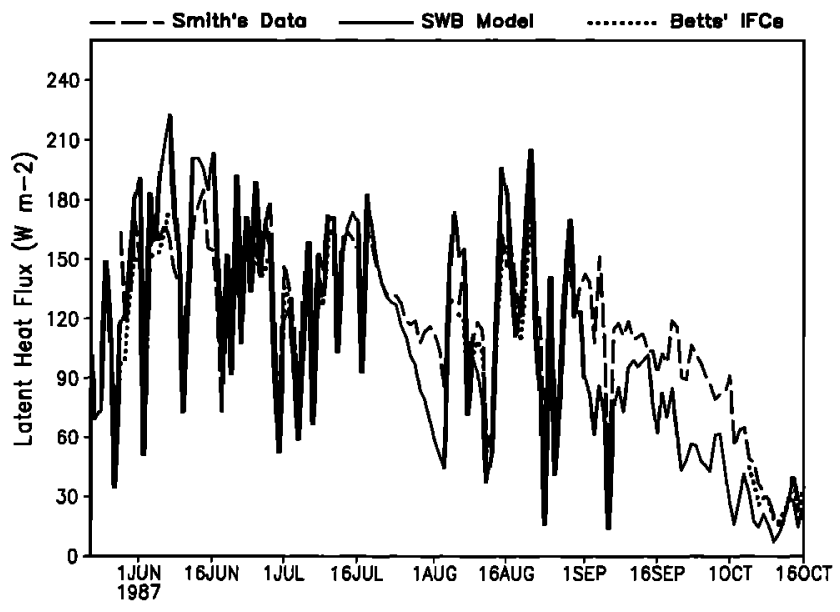

Figure 15. Comparison of daily averaged latent heat fluxes (in watts per square meter) between simulations by the SWB model with a more complex canopy resistance and observations from May 22 to October 16 (compare to Figure 5b).

has a larger resistance than the OSU model for a given soil moisture.

From a number of sensitivity studies it is clear that the inclusion of canopy resistance in the vegetation model provides an important link in the soil-vegetation-atmosphere continuum. For instance, including the canopy resistance in the SWB model noticeably improved the evaporation calculation. With canopy resistance a relatively simple model such as the OSU model was able to capture observed diurnal and seasonal evolution in evaporation and soil moisture, similar to the more sophisticated SSiB model. Therefore understanding how the canopy resistance responds to environment and soil conditions is critical to capturing the diurnal and seasonal evaporation. As the OSU model now stands we found that for this FIFE case, it is important to properly parameterize not only the effect of soil moisture stress but also other canopy resistance factors such as the vapor pressure deficit. In addition, it is important to consider the seasonal cycle of vegetation state, such as the green vegetation fraction, which can significantly improve the evaporation calculation during the canopy green-up and senescence periods.

Both the OSU model and the SSiB model simulated the seasonal evolution of the daily-mean surface skin temperature well; the difference between the simulations and observations was, in general, smaller than $1^{\circ} \mathrm{C}$. The SSiB model produced a smaller diurnal amplitude in surface skin temperature than the OSU model (and observations), a result consistent with the larger thermal inertia inherent in the force restore method in $\mathrm{SSiB}$. It underestimated (overestimated) the daytime maximum (nighttime minimum) skin temperature. The OSU model captured the nighttime skin temperature well, but overestimated the daytime maximum.

This study focused on a 5-month growing and senescence period. As such, we focused on the role of canopy resistance. Yet, recent results in PILPS [Henderson-Sellers et al., 1995] have highlighted the value of intercomparing land surface models on annual and multiyear timescales, including the winter and early spring seasons of snow accumulation and melting. Such annual cycle intercomparisons are not only crucial for GCM climate simulations, but also for the long timescales of either global or regional data assimilation systems, wherein the soil moisture is cycled continuously. Toward this end we have executed and submitted the SWB, OSU, and SSiB models to the 1-year intercomparison of PILPS Phase 2a.

Both the OSU and SSiB model results here suggest that reasonably successful approaches presently exist for canopy resistance. However, the status of runoff treatments is less clear. The runoff responses in the four surface models in the current study were very different. The bucket model generated the least runoff, produced only when the bucket was full. The larger runoff obtained in the OSU model and SWB model was similar as both models shared the same runoff formulation. The SSiB model produced the largest runoff by a significant margin. As the runoff can affect the soil water storage and the partition of available energy into sensible and latent heat fluxes, especially on annual timescales, runoff treatments will receive increasing attention in follow-up studies [e.g., Schaake et al., this issue].

We are currently testing the coupling of the OSU model (using SWB model runoff features) and the SSiB model to the NMC mesoscale Eta model. Herein our efforts are focused on developing detailed spatial fields of (1) vegetation type, seasonal greenness cycle (based on NDVI), soil texture, and topographic characteristics; and (2) parameter values for canopy resistance, runoff, and available water capacity. For spatial parameter estimation over the NWP model domain we are pursuing methodologies to combine hydrological basin calibration techniques with physically deterministic approaches using land surface characteristics.

Acknowledgments. This study was supported by the National Oceanographic and Atmospheric Administration (NOAA) under the National Weather Service (NWS) core GCIP project. Additionally, Yong Kang Xue, Michael Ek, and Alan Betts acknowledge support from NOAA under grants NA46GP0340, NA36GP0369, and NA56GP0380, respectively. We would like to thank Garik Gutman, Satellite Research Laboratory (NOAA/NESDIS), for providing us the seasonal cycle of vegetation greenness fraction over the FIFE area. We wish to express our appreciation to Izuru Takayabu, UCAR/NMC visiting scientist from Japan Meteorology Agency, and Fanrong J. Zeng, Center for Ocean-Land-Atmosphere Studies, for their computing assistance in running the SSiB model.

\section{References}

Acs, F., A coupled soil-vegetation scheme: Description, parameters, validation, and sensitivity studies, J. Appl. Meteorol., 33, 268-284, 1994.

Anthes, R. A., Enhancement of convective precipitation by mesoscale variation in vegetative covering in semiarid regions, J. Clim. Appl. Meteorol., 23, 541-554, 1984.

Avissar, R., and R. Pielke, A parameterization of heterogeneous land surfaces for atmospheric numerical models and its impact on regional meteorology, Mon. Weather Rev., 117, 2113-2136, 1989.

Avissar, R., and M. M. Verstraete, The representation of continental surface processes in atmospheric models, Rev. Geophys., 28, 35-52, 1990.

Betts, A. K., J. H. Ball, and A. C. M. Beljaars, Comparison between the land surface response of the ECMWF model and the FIFE-1987 data, Q. J. R. Meteorol. Soc., 119, 975-1001, 1993.

Black, T., The new NMC mesoscale Eta model: Description and forecast examples. Weather Forecasting, 9, 265-278, 1994.

Blondin, C., Parameterization of land-surface processes in numerical weather prediction, in Land-Surface Evaporation Measurement and Parameterization, edited by T. J. Schmugge and J. C. Andre, Springer-Verlag, New York, 1991.

Blondin, C., and H. Bottger, The surface and sub-surface parameterization scheme in the ECMWF forecasting system: Revision and operational assessment of weather elements, Res. Dep. Tech. Memo. 
135, Eur. Cent. for Medium-Range Weather Forecasting, Reading, Engl., 1987.

Bougeault, P., Parameterization schemes of land-surface processes for mesoscale atmospheric models, in Land-Surface Evaporation Measurement and Parameterization, edited by T. J. Schmugge and J. C. Andre, Springer-Verlag, New York, 1991.

Camillo, P. J., and R. J. Gurney, A resistance parameter for bare-soil evaporation models, Soil Sci., 2, 95-105, 1986.

Chen, F., and R. Avissar, The impact of land-surface wetness on mesoscale heat fluxes, J. Appl. Meteorol., 33, 1324-1340, 1994a.

Chen, F., and R. Avissar, Impact of land-surface moisture variability on local shallow convective cumulus and precipitation in large-scale models, J. Appl. Meteorol., 33, 1382-1401, 1994b.

Cosby, B. J., G. M. Hornberger, R. B. Clapp, and T. R. Ginn, A statistical exploration of the relationships of soil moisture characteristics to the physical properties of soils, Water Resour. Res., 20, 682-690, 1984.

Cuenca, R. H., M. Ek, and L. Mahrt, Impact of soil water property parameterization on atmospheric boundary-layer simulation, this issue.

Deardorff, J. W., Efficient prediction of ground surface temperature and moisture, with inclusion of a layer of vegetation, $J$. Geophys. Res., 83, 1889-1903, 1978.

Dickinson, R. E., Modeling evapotranspiration for three-dimensional global climate models, in Climate Processes and Climate Sensitivity, Geophys. Monogr. Ser., vol. 29, edited by J. E. Hansen and T. Takahashi, pp. 58-72, AGU, Washington, D. C., 1984.

Duan, Q. Y., J. C. Schaake, and V. I. Koren, FIFE 1987 water budget analysis, this issue.

Ek, M., and L. Mahrt, OSU 1-D PBL model user's guide, Dep. of Atmos. Sci., Oreg. State Univ., Corvallis, Oreg., 1991.

Entekhabi, D., and P. S. Eagleson, Land surface hydrology parameterization for atmospheric general circulation models including subgrid scale variability, J. Appl. Meteorol., 2, 817-831, 1989.

Garratt, J. R., Sensitivity of climate simulations to land-surface and atmospheric boundary-layer treatments-A review, J. Clim., 6, 419$449,1993$.

Gutman, G., D. Tarpley, A. Ignatov, and S. Olson, The enhanced NOAA global land dataset from the advanced very high resolution radiometer, Bull. Am. Meteorol. Soc., 76, 1141-1156, 1995.

Hanks, R. J., and G. L. Ashcroft, Applied Soll Physics, 159 pp., Springer-Verlag, New York, 1986.

Henderson-Sellers, A., A. J. Pitman, P. K. Love, P. Irannejad, and T. $H$. Chen, The project for intercomparison of land surface parameterization schemes (PILPS): Phase 2 and 3, Bull. Am. Meteorol. Soc., 76(4), 489-503, 1995.

Hillel, D., Applications of Soil Sctences, Academic, San Diego, Calif., 1980.

Jacquemin, B., and J. Noilhan, Sensitivity study and validation of a land surface parameterization using the HAPEX-MOBILHY data set, Boundary Layer Meteorol., 52, 93-134, 1990.

Janjic, Z. I., The step-mountain Eta coordinate model: Further development of the convection, viscous sublayer, and turbulence closure schemes, Mon. Weather Rev., 122, 927-945, 1994.

Jarvis, P. G., The interpretation of the variation in leaf water potential and stomatal conductance found in canopies in the field, Philos. Trans. R. Soc. London B, 273, 593-610, 1976.

$\mathrm{Kim}, \mathrm{J}$, and M. Ek, A simulation of the surface energy budget and soil water content over the HAPEX-MOBILHY forest site, J. Geophys. Res., 100, 20,845, 1995.

$\mathrm{Kim}, \mathrm{J}$., and S. Verma, Components of surface energy balance in a temperate grassland ecosystem, Boundary Layer Meteorol., 51, 401$417,1990$.

Mahfouf, J. F., E. Richard, and P. Mascart, The influence of soil and vegetation on the development of mesoscale circulations, J. Clim. Appl. Meteorol., 26, 1483-1495, 1987.

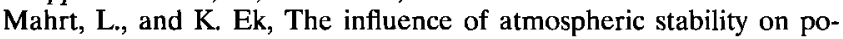
tential evaporation, J. Clim. Appl. Meteorol., 23, 222-234, 1984.

Mahrt, L., and H. L. Pan, A two-layer model of soil hydrology, Boundary Layer Meteorol., 29, 1-20, 1984.

Manabe, S., Climate and the ocean circulation, 1, The atmospheric circulation and the hydrology of the earth's surface, Mon. Weather Rev., 97, 739-774, 1969.

Mintz, Y., The sensitivity of numerically simulated climates to land surface boundary conditions, Proc. JSC Study Conf. on Land Surface Processes in Atmos. GCM, Greenbelt, Md., 1981.
Noilhan, J., and S. Planton, A simple parameterization of land surface processes for meteorological models, Mon. Weather Rev., 117, 536549, 1989.

Ookouchi, Y., M. Segal, R. C. Kesseler, and R. Pielke, Evaluation of soil moisture effects of the generation and modification of mesoscale circulations, Mon. Weather Rev., 112, 2281-2292, 1984.

Pan, H.-L., A simple parameterization scheme of evapotranspiration over land for the NMC medium-range forecast model, Mon. Weather Rev., 118, 2500-2512, 1990.

Pan, H.-L., and L. Mahrt, Interaction between soil hydrology and boundary-layer development, Boundary Layer Meteorol., 38, 185$202,1987$.

Pleim, J. E., and A. Xiu, Development and testing of a surface flux and planetary boundary layer model for application in mesoscale models, J. Appl. Meteorol., 34, 16-32, 1995.

Robock, A., K. Vinnikov, C. A. Schlosser, N. A. Speranskaya, and Y. $\mathrm{K}$. Xue, Use of midlatitude soil moisture and meteorological observations to validate soil moisture simulations with biosphere and bucket models, J. Clim., 9, 15-35, 1995.

Rowntree, P. R., Sensitivity of GCM to land surface processes, Proc. Workshop in Intercomparison of Large Scale Models for Extended Range Forecasts, pp. 225-261, Eur. Cent. for Medium-Range Weather Forecasts, Reading, Engl., 1983.

Rowntree, P. R., and J. R. Bolton, Simulations of the atmospheric response to soil moisture anomalies over Europe, Q.J. R. Meteorol. Soc., 109, 501-526, 1983.

Schaake, J. C., V. I. Koren, Q. Y. Duan, K. Mitchell, and F. Chen, Simple water balance model for estimating runoff at different spatial and temporal scales, this issue.

Sellers, P. J., Y. Mintz, Y. C. Sud, and A. Dalcher, A simple biosphere model (Sib) for use within general circulation models, J. Atmos. Scl., 43, 505-531, 1986.

Sellers, P. J., F. G. Hall, G. Asrar, D. E. Strebel, and F. F. Murphy, An overview of the First International Satellite Land Surface Climatology Project (ISLSCP) Field Experiment (FIFE), J. Geophys. Res., 97, 18,345-18,371, 1992a.

Sellers, P. J., M. D. Heiser, and F. G. Hall, Relations between surface conductance and spectral vegetation indices at intermediate $\left(100 \mathrm{~m}^{2}\right.$ to $15 \mathrm{~km}^{2}$ ) length scales, J. Geophys. Res., 97, 19,033-19,059, 1992b.

Smith, E. A., W. L. Crosson, and B. D. Tanner, Estimation of surface heat and moisture fluxes over a prairie grassland, 1, In situ energy budget measurements incorporating a cooled mirror dew hygrometer, J. Geophys. Res., 97, 18,557-18,582, 1992.

Stewart, J. B., and S. B. Verma, Comparison of surface fluxes and conductances at two contrasting sites within the FIFE area, J. Geophys. Res., 97, 18,623-18,628, 1992.

Viterbo, P., and A. C. Beljaars, An improved land surface parameterization scheme in the ECMWF model and its validation, J. Clim., in press, 1995.

Wetzel, P., and J. T. Chang, Concerning the relationship between evapotranspiration and soil moisture, J. Clim. Appl. Meteorol., 26, $18-27,1987$.

Wood, E. F., D. P. Lettenmaier, and V. G. Zartarian, A land-surface parameterization with subgrid for general circulation models, $J$. Geophys. Res., 97, 2717-2728, 1992.

Xue, Y., P. J. Sellers, J. L. Kinter, and J. Shukla, A simplified biosphere model for global climate studies, J. Clim., 4, 346-364, 1991.

Xue, Y., H. G. Bastable, P. A. Dirmeyer, and P. J. Sellers, Sensitivity of simulated surface fluxes to changes in land surface parameterizations-A study using ABRACOS data, J. Appl. Meteorol., in press, 1995.

A. Betts, Atmospheric Research, R.R. 2, Box 2602, Pittsford, VT 05763. F. Chen, K. Mitchell, and H.-L. Pan, Development Division, Environmental Modeling Center, NWS/NOAA, W/NMC22, WWB, Rm. 204, 5200 Auth Rd., Camp Springs, MD 20746. (e-mail: fchen@sunl.wwb.noaa.gov)

Q. Y. Duan, V. Koren, and J. Schaake, Office of Hydrology, NWS/ NOAA, 1325 East-West Highway, Silver Spring, MD 20910.

M. Ek, College of Oceanic and Atmospheric Sciences, Oregon State University, Corvallis, OR 97331.

Y. Xue, Center for Ocean-Land-Atmosphere Studies, 4041 Powder Mill Rd., Calverton, MD 20705-3106.

(Received March 7, 1995; revised July 7, 1995; accepted July 7,1995 .) 